العدد الحادي والأربعون

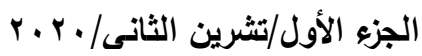

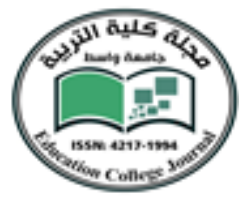

\title{
أثر العوامل الطبيعة في قوة سلطنة بروناي \\ دراسة في الجغرافية السياسية
}

أ.م.د. أسراء كاظم جاسم الحسيني

جامعة واسط / كلية التربية للعلوم الانسانية

israakr@uowasit.edu.iq

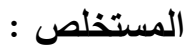

يهذف البحث إلى دراسة أثز العوامل الطبيعية في قوة سلطنة بروناي، أذ شهر تاريخها الكثير

من الاحداث السياسية والاقتصادية منذ القرن الاول الميلادي حتى عام عه919 بعد أن تخلصت

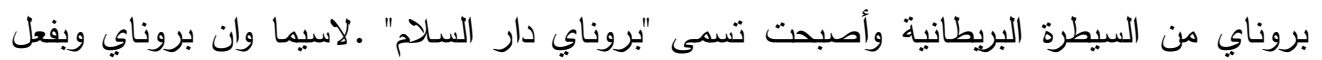
موقعها الجغرافي "الفلكي" أذ تقع بروناي داخل نطاق المناخ المداري المطير ((الاستوائي البحري))

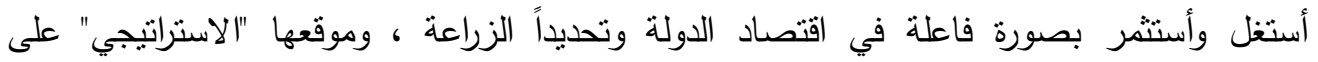

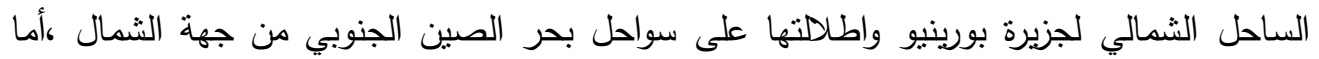

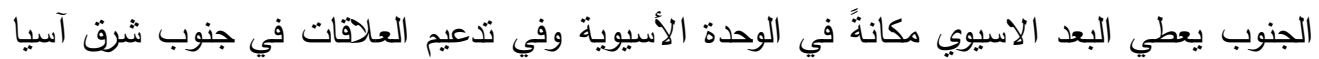

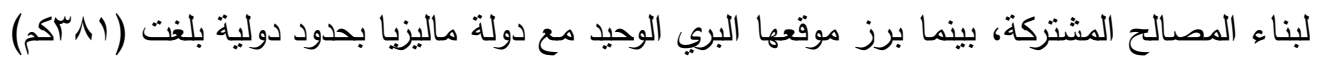
ورغم مساحة الدولة الصغيرة الا انها تعد عنصر القوة المكانية المتعددة في معادلة كثف القوة

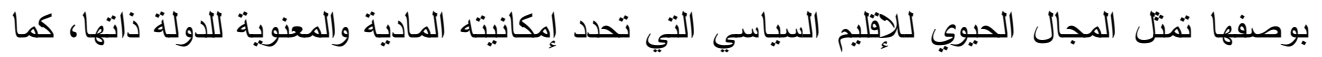
بينت الدراسة مساحة وشكل سلطنة بروناي التي تعد احد الجوانب الايجابية عند التقييم الجيوبوليتيكي لها، كما ان قسمي بروناي الغربي والثرقي وهامشية مركزية الدولة وموقع عاصمتها قد افقدها كثيرا

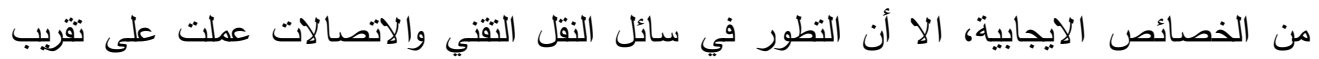
المسافات بين اجزائها وفضلا عن التكنولوجيا العسكرية الني لا يستهان بها لدرء الخطر عنها ،وعليه

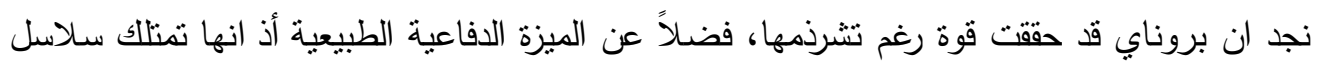

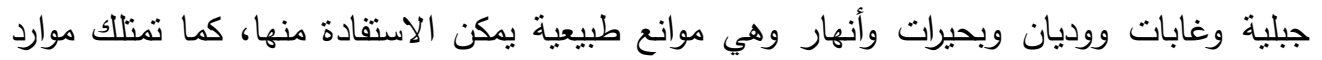
طبيعية منها (الثروة الغابية ) الغنية التي تغطي •v\% من مساحة الدولة، و (الثروة المعدنية) منها النفط بحقولها البرية والبحرية والغاز الطبيعي التي احتلت به مراكز منقدمة بين دول الاسيوية يعد عائداً كبيرا للدولة وقوتها الاقتصادية والمادية.

وعززت الدراسة التي بنيت على المنهجين التاريخي والتحليلي بمجموعة من الخرائط والجداول

والمصادر العربية والاجنبية وختم الدراسة بمجموعة الاستنتاجات . 


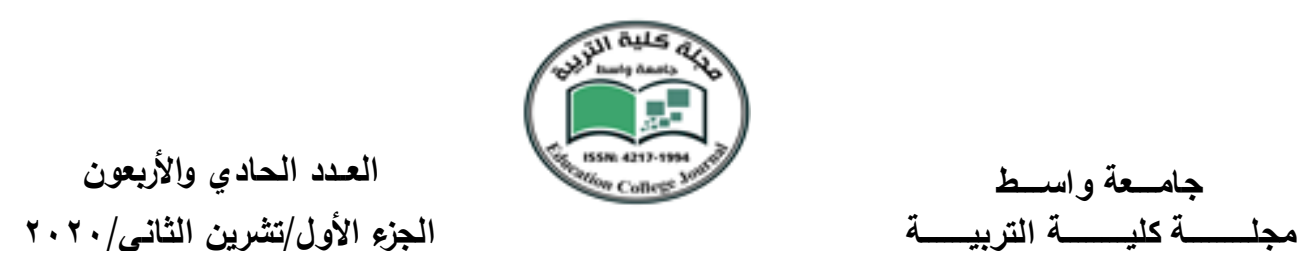

\section{Abstract :}

The research aims to study the effect of natural factors on the power of Brunei sultanate. This is because its history witnessed many political and economic events from the first century AD until 1984 after Brunei got rid of British control and started to be called "Brunei Peace Home." Brunei is located within a tropical rainy climate ((tropical marine)). Such a position has been invested in favor of the country's economy, specifically in agriculture. Besides, it is characterized by its strategic location on the northern coast of the island of Borneo; it overlooks the coasts of South China Sea from the north. The south, on the other hand, gives the Asian dimension a position in the Asian unity. It further strengthens the relations in Southeast Asia to build common interests. Moreover, its land location with the State of Malaysia amounts to $381 \mathrm{~km}$. Despite the small size of the state, it is considered a multiple spatial power component in the power-detection equation. This is because it represents the vital field of the political region that determines its material and moral potential for the state itself. The study has further showed the area and shape of the Sultanate of Brunei, which is one of the positive aspects when evaluating its geopolitical position. The Western and Eastern parts of Brunei, the marginal centralization of the state and the location of its capital have made it lose many of the positive characteristics. However, the development in the means of technical transportation and communication worked to bring the distances between its parts closer, in addition to the military technology that is not negligible to ward off the danger. Accordingly, one can find that Brunei has achieved strength despite its fragmentation due to the natural defensive advantage represented by its mountain ranges, forests, valleys, lakes and rivers, which all represent natural barriers that can be used. In addition, it possesses natural resources, including rich (forest wealth) that covers $70 \%$ of the state's area, and (Mineral wealth), including the oil in its onshore and offshore fields and the natural gas, which all occupied advanced positions among the Asian countries. All these resources represent a great return to the state and its economic and material strength. The study, which was based on the historical and analytical approaches, has been reinforced by a set of Arab and foreign maps, tables, and sources. It finally ended with a set of conclusions and recommendations. 
العدد الحادي والأربعون

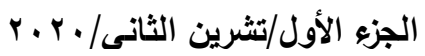

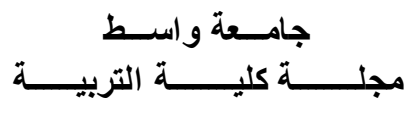

المقدمة:

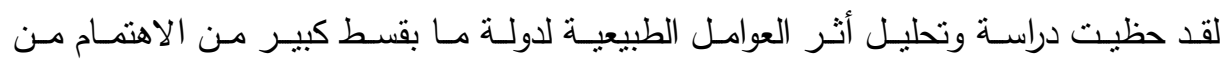

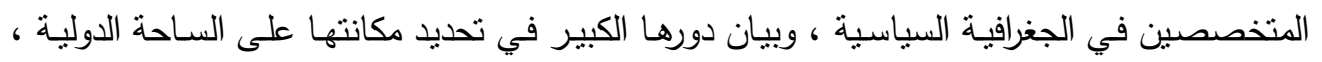

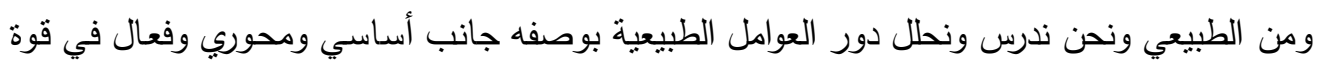

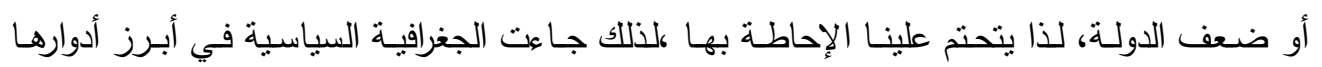
لتكثف دور العوامل الطبيعية لدولة إسلامية صغيرة من بين دول جنوب شرق آسيا إلا وهي سلطنه

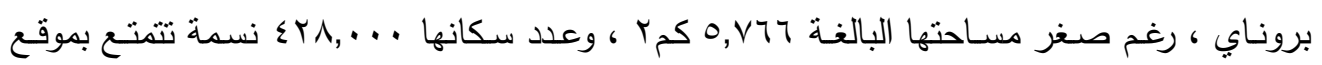

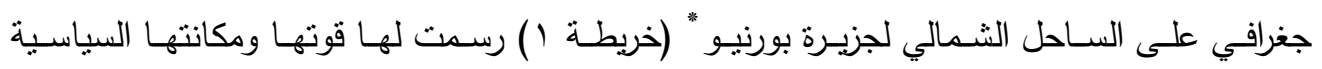

والاقتصادية النفطية .

\section{(خريطة ()}

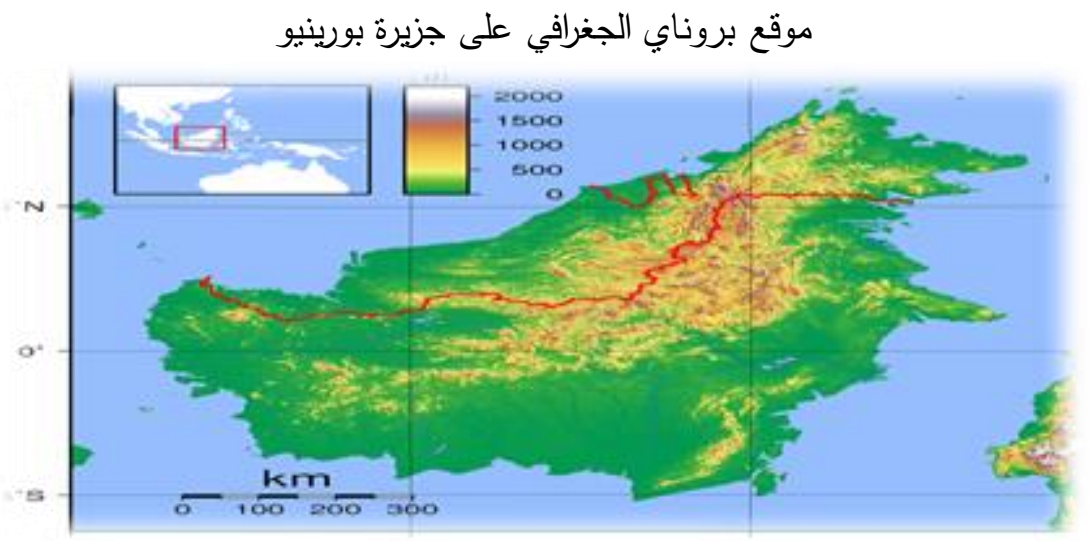

المصدر : الباحثة بالاعتماد

"URI://http://Www و ويكيبيديا، الموسوعة الحرة, Retrieved on Wed. 10, August, 2020.

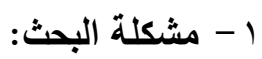

تعد العوامل الطبيعية أحدى عناصر قوة الدولة ـ فهل يمكن لهذه العوامل ان تكون مصدراً للقوة

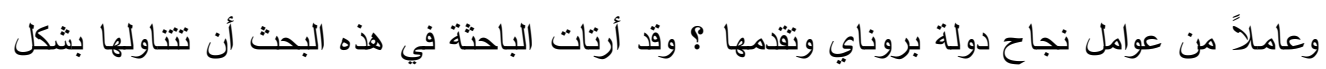

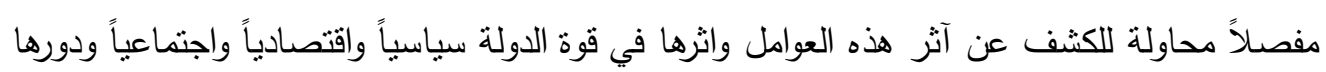
في بناء القوة الذانية لدولة بروناي تميزت بتتوعها الطبيعي والبشري. 
العدد الحادي والأربعون

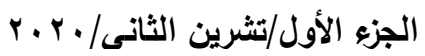

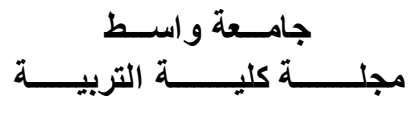

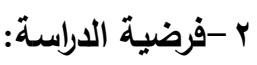

تقوم الدراسة بشكل اساسي على التحقق من العوامل الطبيعية لدولة بروناي اخذين بعين الاعتبار كل العوامل الطبيعية التي لها ارتباط واضح في مسار قوة دولة بروناي،وهذا الارتباط يمكن تفسيره جغرافيا في ضوء تلك العوامل التي تطبعت وأثرت بالدولة وسكانها والتي يمكن صباغتها على النحو الآتي:

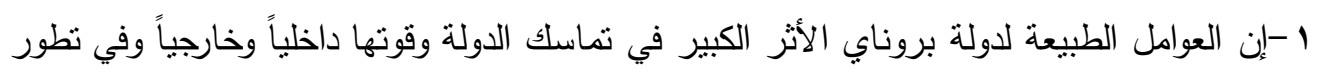

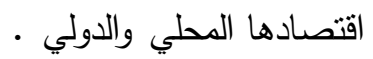

ץ-للعوامل الطبيعية أثر واضح في استقرار بروناي وفي رسم وتحديد مستقبلها الجيوبوليتيكي.

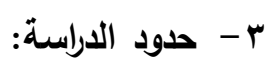

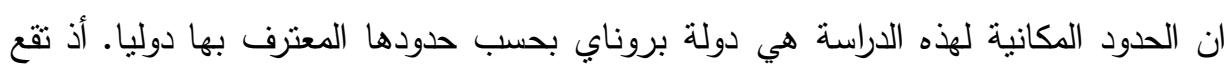

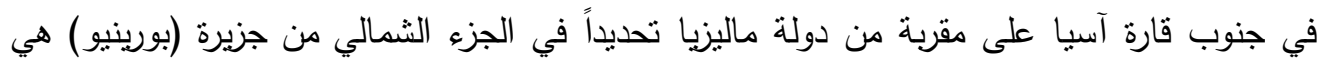

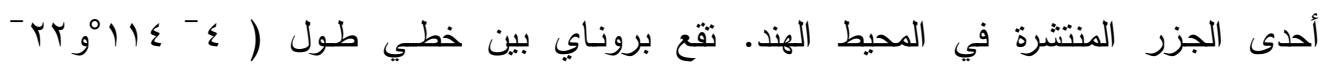

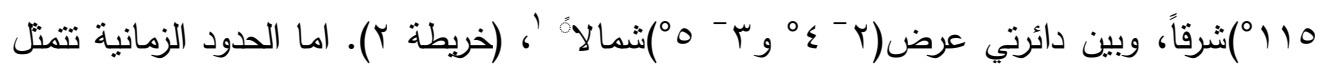

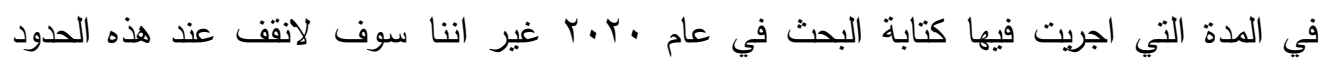
الزمانية وفقاً لمقتضيات البحث ومرجعياته.

(خريطة ( )

الموقع الجغرافي لسلطنة بروناي

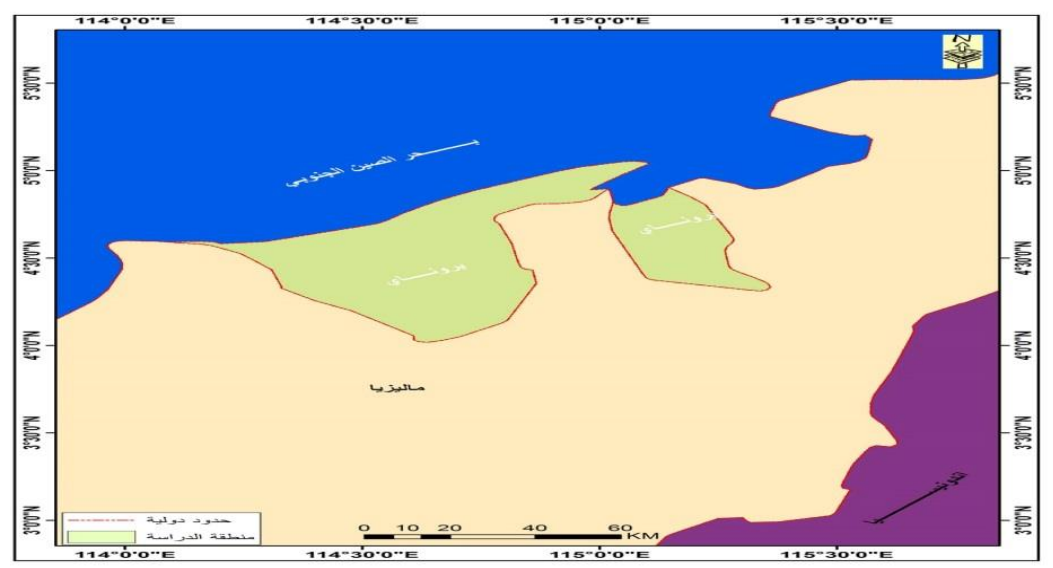

المصدر: الباحثة بالاعتماد على

Concise Atlas of the World, Collins Publishers, London,2010,p.116. 


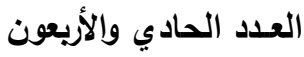

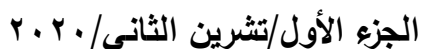

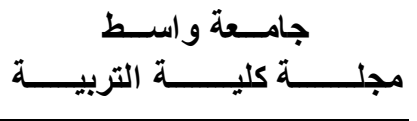

ع - منهجية الدراسة :

اعتمدت الباحثة على منهجين للوصول الى غاية الدراسة وهي:

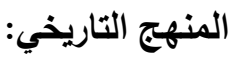

اذ يرتكز هذا المنهج على الماضي في تحليل الاحداث الحاضرة والمستقبلية لتاريخ الدولة مما يمكن هذا المنهج الباحثة من فهم ظروف الحاضر السياسية وطبيعة العلاقة بين البيئة والدولة. المنهج التحليلي: المنال

يُعنى هذا المنهج في تحليل قوة الدولة من الناحية الجغرافية وتحليل العوامل الطبيعية المؤثرة في

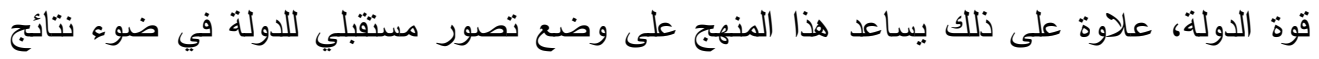

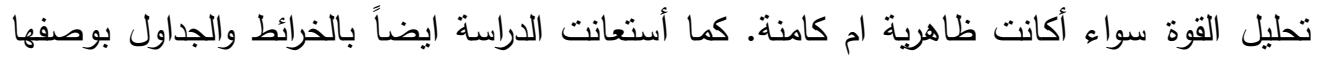
وسيلة جغرافية للوصول الى الهدف . ع - اسباب اختيار الدراسة وأهميتها:

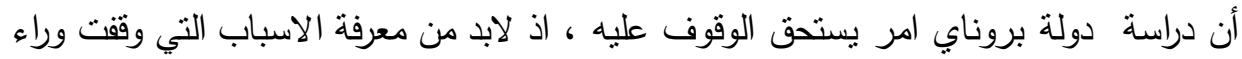

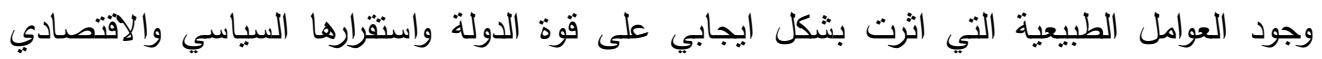

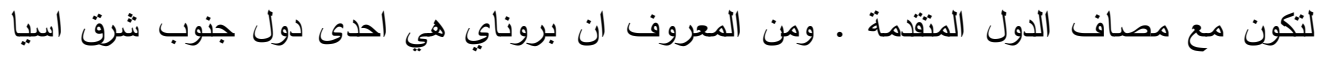

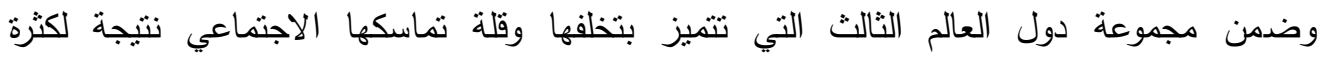

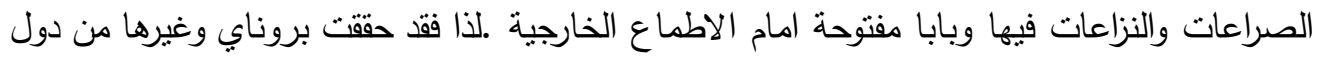

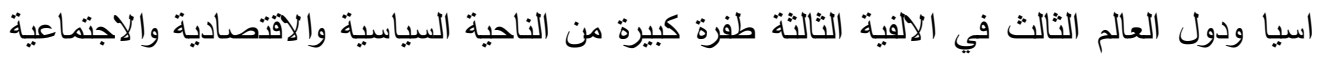

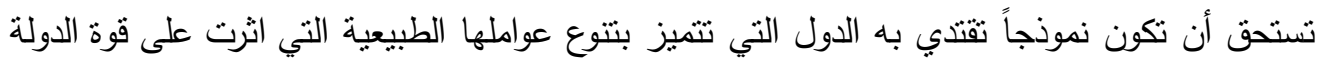
ايجابياً.

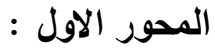
نبذه تاريخية عن نشأة سلطنة بروناي تشير الأحداث التاريخية عن وجود تبادل تجاري بين بروناي والتجار الهنود منذ القرن الأول

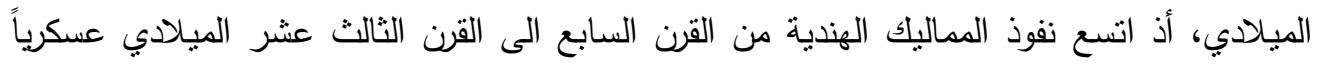
على ارض بروناي'، وفي الوقت نفسه خضعت بروناي للسيطرة الصينية أذ كانت تمثل مركزاً تجارياً

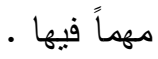

في القرن الخامس عشر الميلادي تحول ملوك سلطنة بروناي الى الإسلام ، عندما اعتتق

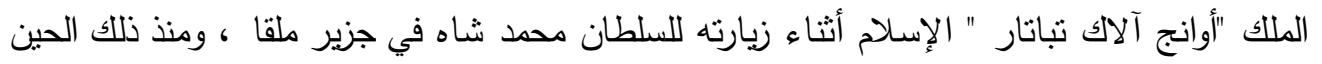


العدد الحادي والأربعون

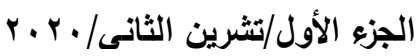

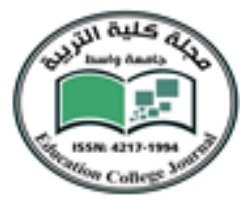

اصبح حكام بروناي يلقبون بالسلطان ، وقد اعزهم الاسلام فزادت قوتهم واتسع نفوذهم ، وفي نهاية القرن نفسه ، تخلصوا من نفوذ سلطان ملقا ، واصبح لسلاطين بروناي السيطرة على كل سواحل

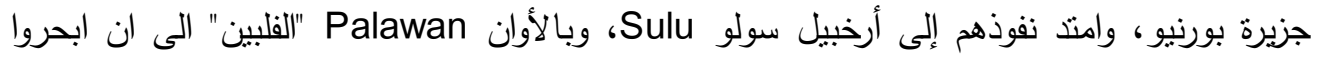
ووصلوا الى جاوه عاص حتى نم فتح مانيلا واستولى عليها على بد أحد السلاطين ويسمى بولى بلقيه

في عام OYl

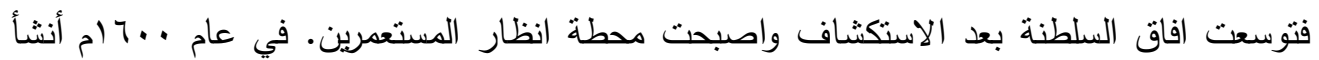

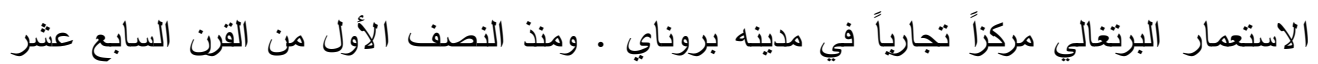

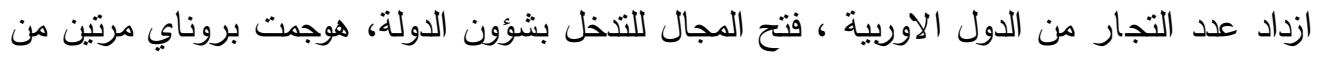

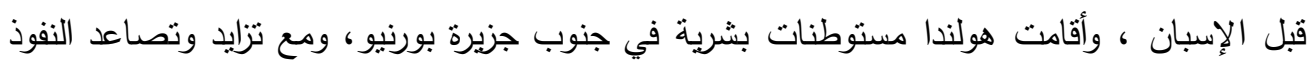

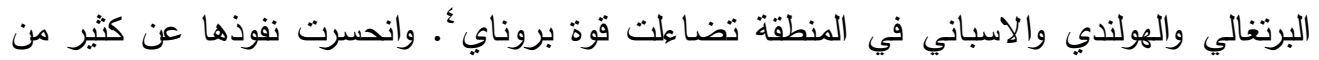

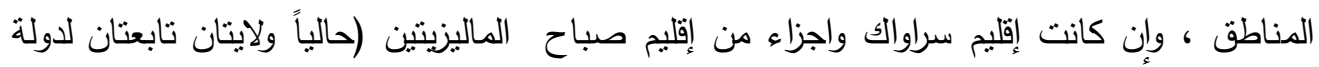

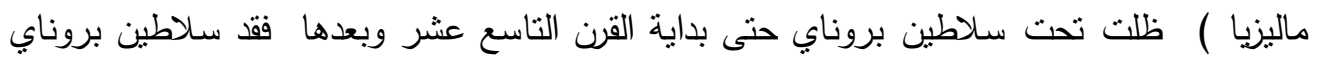

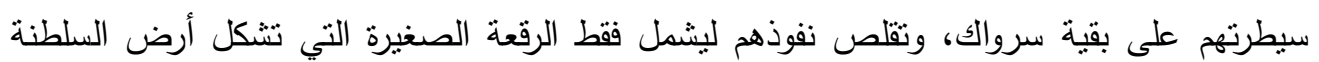
حالياً.

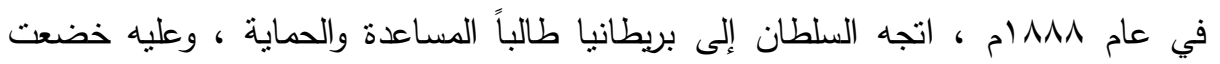

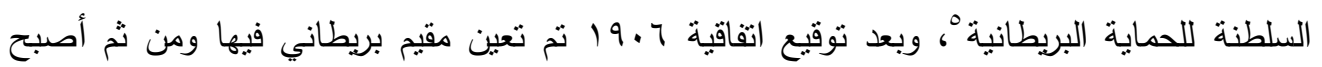

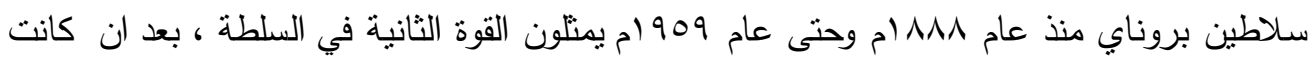

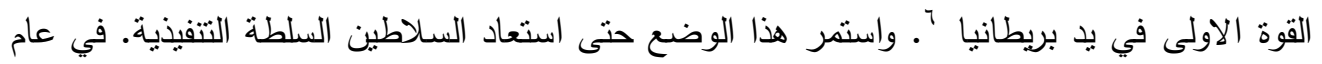
1909 وضع أول دستور للبلاد، نص على نأليف مجلس استشاري وقانوني يساعد السلطان في إدارة

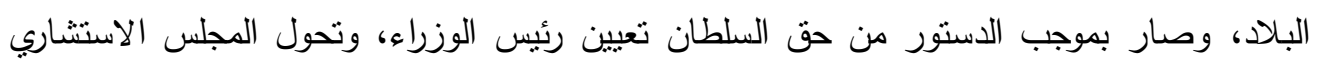

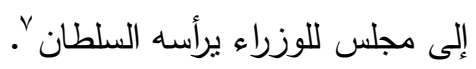

في عام سجو ام، رفضت بروناي للانضمام لاتحاد ماليزيا وآترت البقاء خارج الاتحاد . واضطرت بريطانيا أمام الضغط المتزايد من جانب السلطان ان تمنح بروناي الحكم الذاتي عام

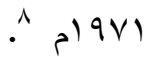

في عام 9V9 ام، وقعت اتفاقية بروناي لإنهاء سيطرة بريطانيا على الثؤون الخارجية

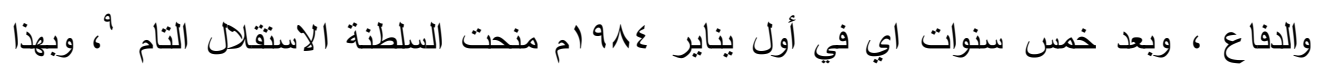


العدد الحادي والأربعون

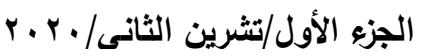

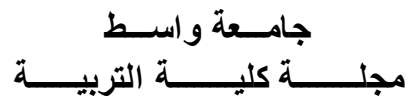

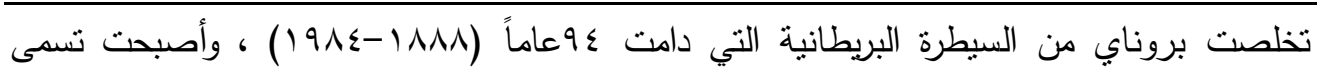

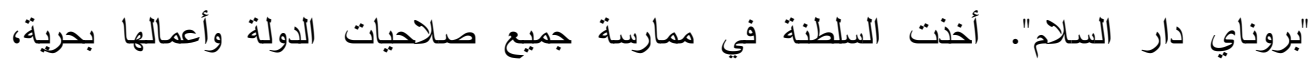
كأنضمامها الى منظمة الأمم المتحدة في 9 اسبتمبر عد9 (م، أذ أصبحت العضو رقم (109)، وكما انضمت إلى المؤتمر الإسلامي في السنه ذاتها وأصبحت عضواً في منظمة دول جنوب شرق آنس آسيا

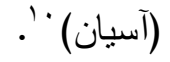

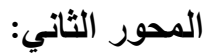
العوامل الجغرافية الطبيعية في سلطنة بروناي أن تحليل الدولة للعوامل الطبيعية في الجغرافية السياسية لها الاثر في قيمة الدولة سياسياً

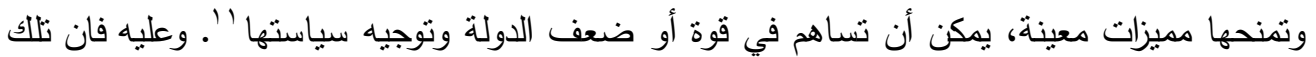

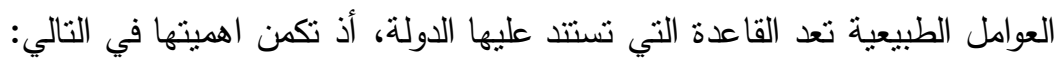
1 - تأثنر الموارد الطبيعية في تركيب الدولة السياسي والاقتصادي والاجتماعي. r - أن دراسة التركيب الطبيعي للدولة تساعد الباحثنين والمخططين في نقرير أهميته الدولة و ووزنها

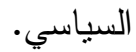
r - تمكين سهوله النوسع أو التعرض للهجوم او في حالة مقاومة الحصار الخارجي .

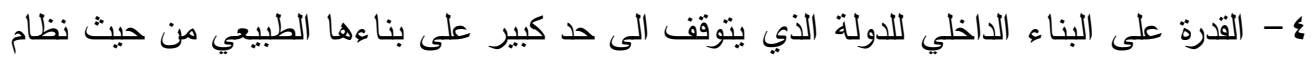

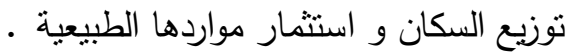

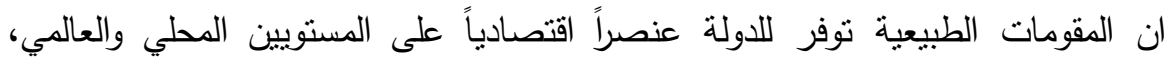

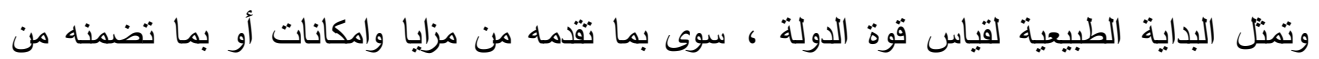

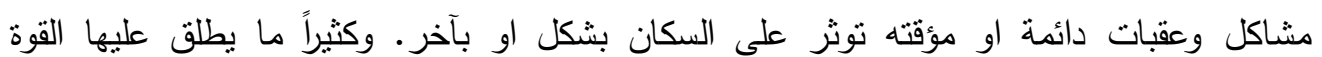

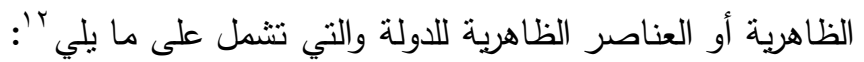

\section{Geographical Location أولاً:- الموقع الجغرافي}

يعد الموقع الجغرافي الاساس في التحليل الجغرافي السياسي لأي كيان سياسي سواء دولةًً او حلفاً

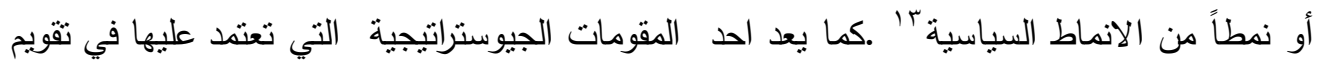

وزن الدولة السياسي ، بسبب تأثيرها الواضح على وضع الدولة الحالي ومستقبلها الجيوبوليتيكي ؛ '.

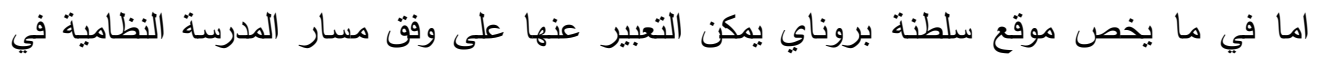

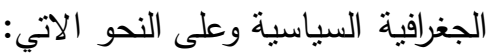


العدد الحادي والأربعون

الجزء الأول/تثرين الثانى/.r. r. r

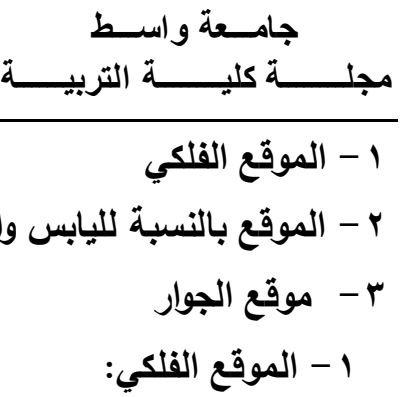

يقصد بالموقع الفلكي الموقع قياساً لخطوط الطول ودوائر العرض ، وتتمنل الأهمية هذا التقسيم في

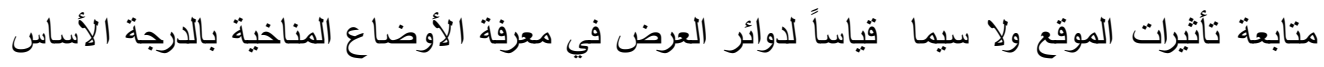

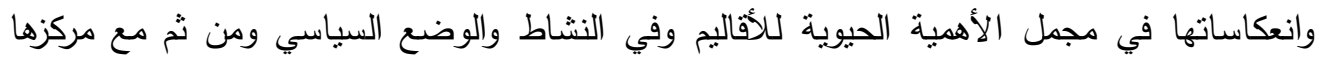
الدولي

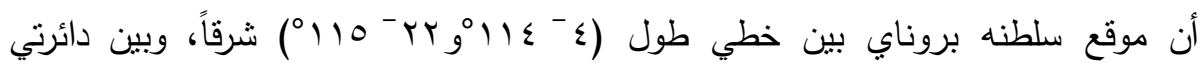

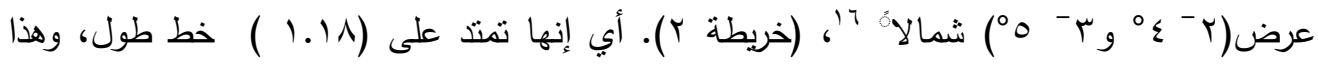

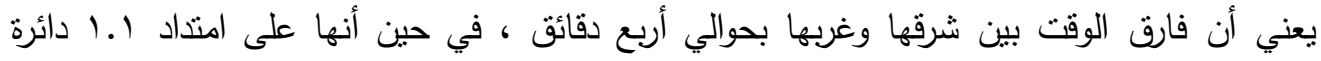

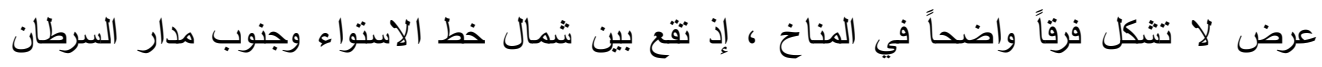

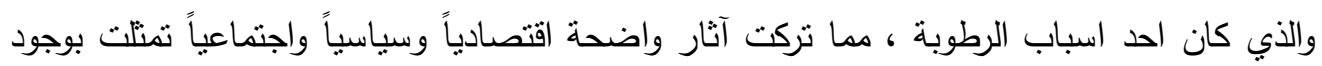

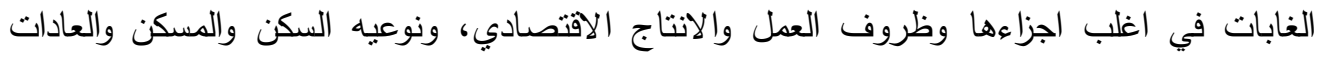
والثقاليد الاجتماعية، فضلا عن طبيعة النظام السياسي. ونستتنج مما سبق أن الموقع الفلكي في الدول الصغيرة يؤثر سلباً أكثر منه في الدول الكبيرة إذ أن صغر المساحة والامنداد القليل بين دوائر العرض يفرض فئ نوعاً منفرداً من المناخ إلا أن سلطنه بروناي تثنذ عن هذه القاعدة بسبب تتوع التضاريس مما زودها بمناخات مختلفة وبيئات منتوعة

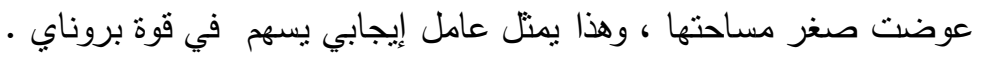
r ألموقع بالنسبة لليابس والماء أن موقع الدولة من البحر واليابس نتوقف على مجموعة من العلاقات التي تربط هذه الدولة بغيرها،

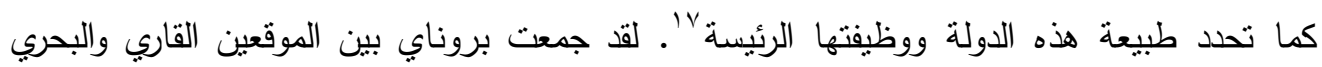

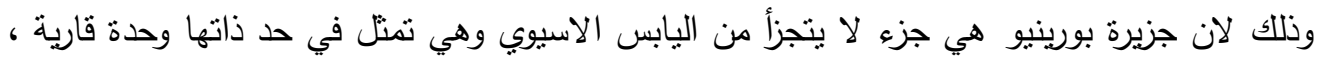

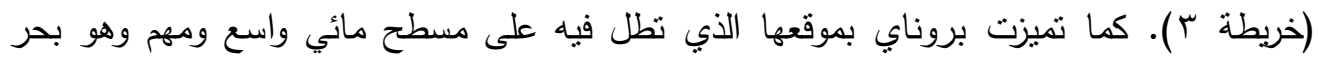

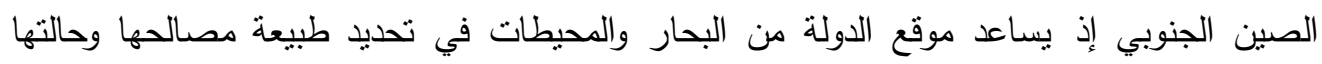

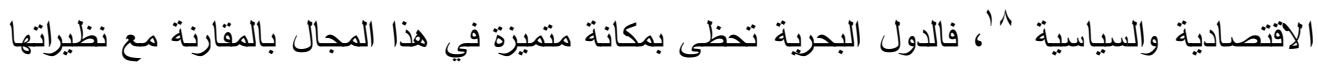

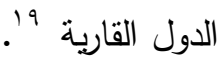


العدد الحادي والأربعون

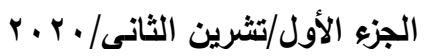

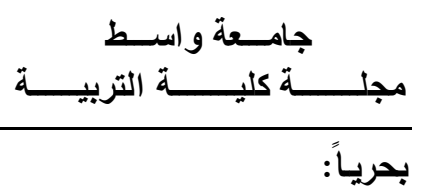

تقع بروناي على الساحل الشمالي لجزيرة بورينيو ولها اطلاده على سواحل بحر الصين الجنوبي

من جهة الثمال ، إذ يبلغ الثريط الساحلي لها (ا7 (اكم) وحقوق الهطالبة البحرية ( المياه

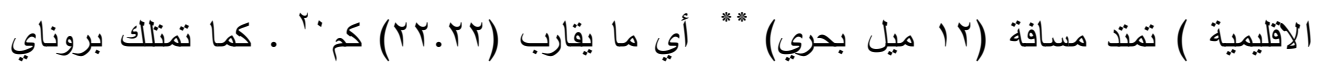

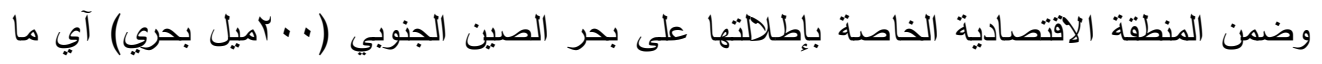

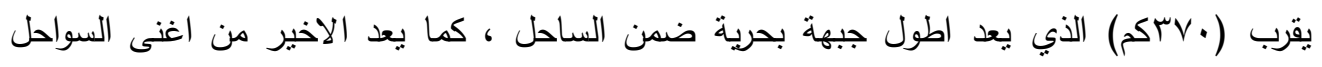

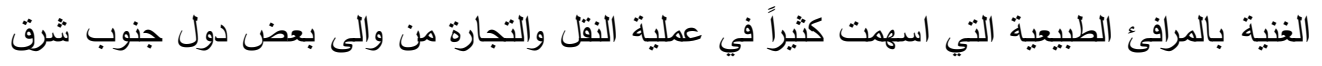
اسيا والعالم لقربها من الممرات البحرية في بحر الصبن الجنوبي التي تربط المحيطين الهندي والهادي

$$
\text { (خريطة r) }
$$

موقع سلطنة بروناي بالنسبة لليابس والماء

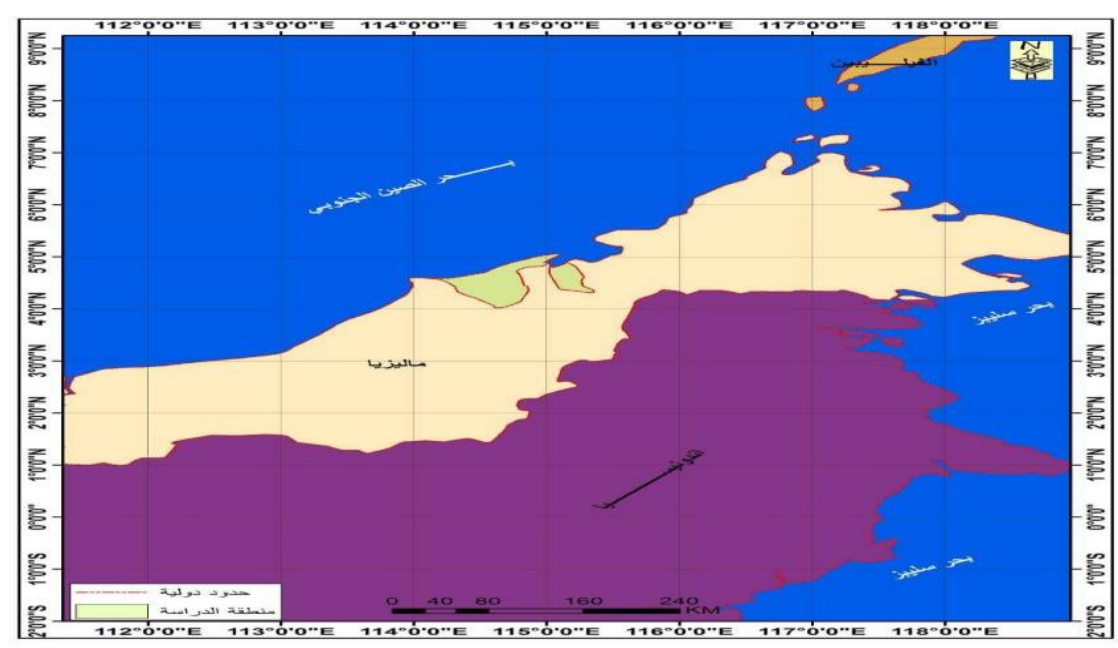

\section{المصدر: الباحثة بالاعتماد على}

- Concise Atlas of the World, Collins Publishers, London,2010,p .116.

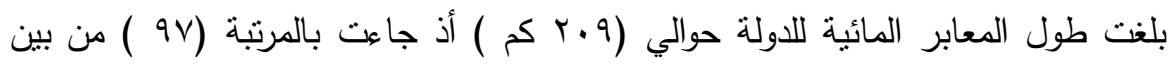

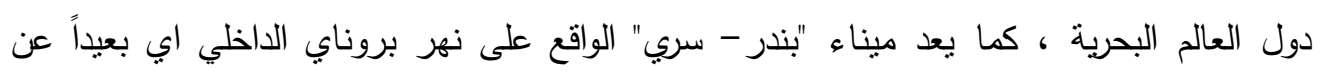

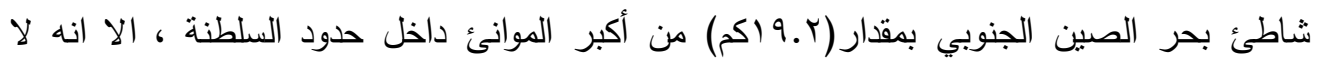

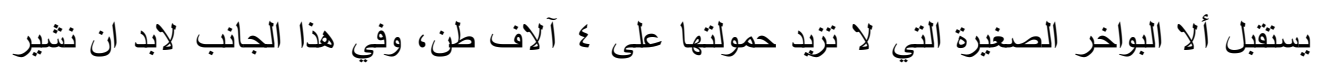

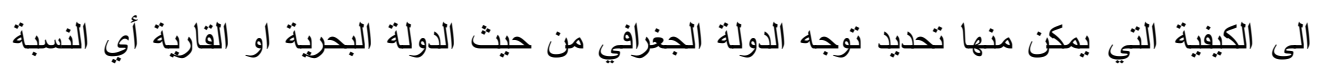

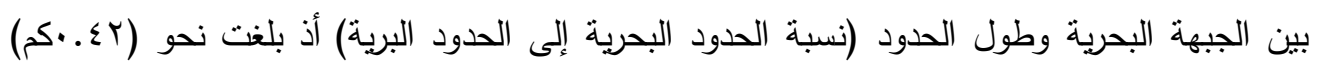


العدد الحادي والأربعون

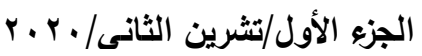

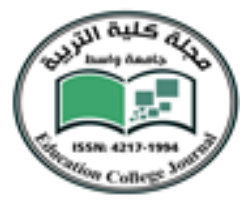

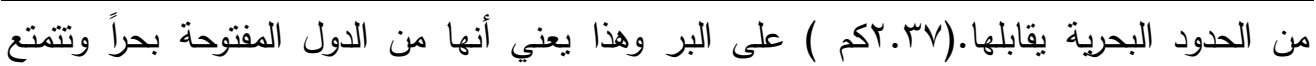

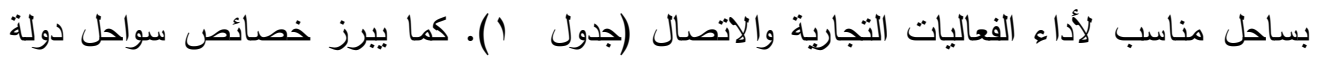

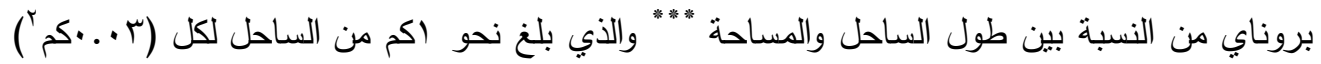
تقريباً من المساحة ويثبر ذلك إلى نوغل المساحة نحو الداخل عمقاً .

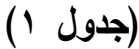

مساحة ونسب الحدود البرية والبحرية لسلطنة بروناي

\begin{tabular}{|c|c|c|c|c|c|c|c|}
\hline 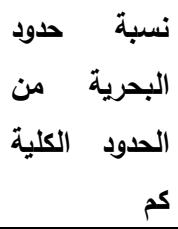 & لمبة البرية & البحرية الحدود البى & مجموع & البحرية & البرية كم & كمرّ المسية & الدولة \\
\hline r.A & 7.7 & $1.7 r$ & $0 \leqslant Y$ & 171 & rs & 0.174 & بروناي \\
\hline
\end{tabular}

المصدر : الباحثة بالاعتماد على

Ravi Shekhar Singh, Asian Strategic and Military Perspective, New Delhi: Lancer Publishers, 2005, p. 180.

وعلى الرغم من أهمية الموقع الجغرافي للاولة البحرية فأن نوع الساحل هو المعيار الذي بمكن أن يساعد الباحث في عملية النقييم، لمعرفة القيمة الفعلية لهذه السواحل، وتتوقف القيمة الفعلية للجبهة البحرية على الظهير الخلفي للساحل "r ويكتسب الساحل البروناوي أهيته كونه منطقة التركز

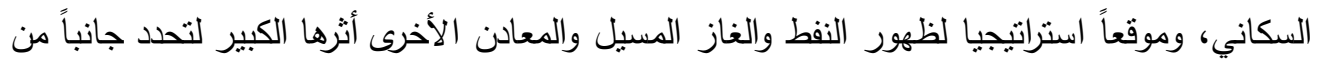
تتامي أهمية الموقع، لذلك كان لظهير الجبهة البحرية تأثير كبير على أهية السواحل البراونية سكانياً واقتصنادياً وسياسياً.

ولكون بروناي شبه جزريه لهذا النمط من المواقع مزايا اقتصادية وعسكرية وسياسية ، فسكان

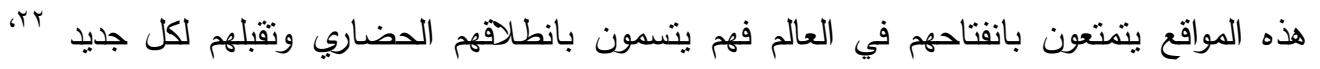

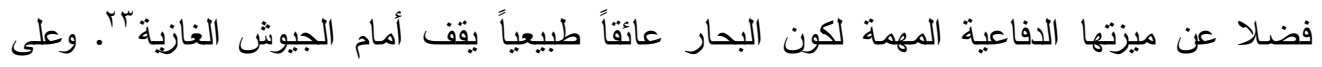

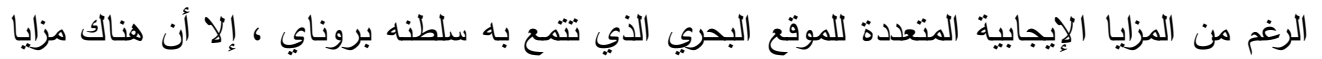

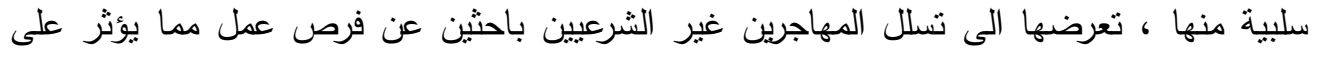
اقتصاد الدولة ، كما ان الدول الصغيرة متل سلطنه بروناي ، يعرضها للضغط الثنديد من أجل كسبها

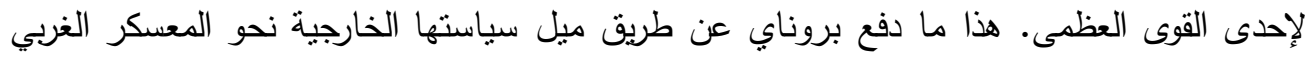


العدد الحادي والأربعون

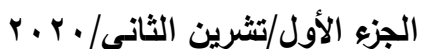

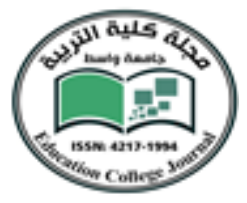

قاريـاً: يعكس الموقع القاري أثاره الايجابية والسلبية تبعاً لإيجابية وسلبية العلاقة الدولية بين هذه

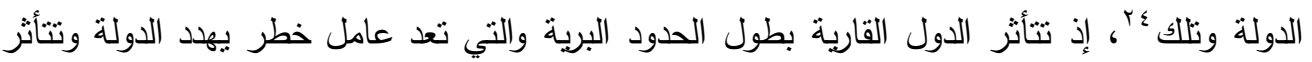

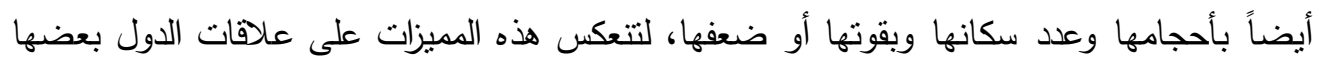

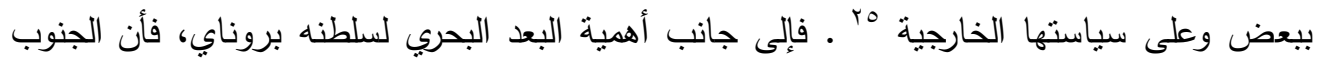

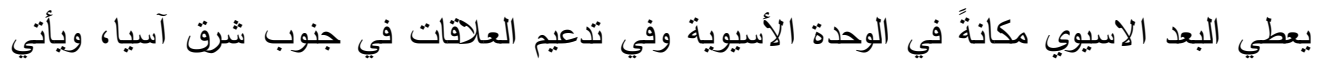

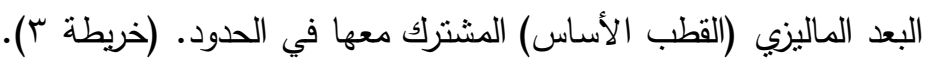

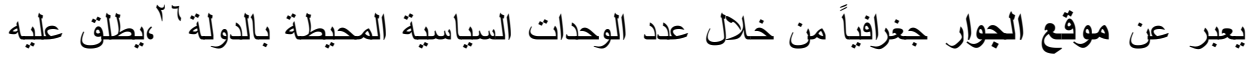

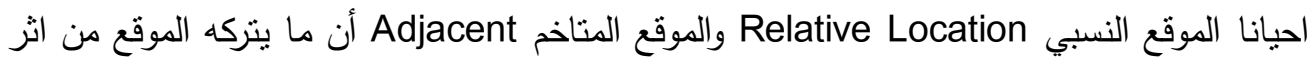

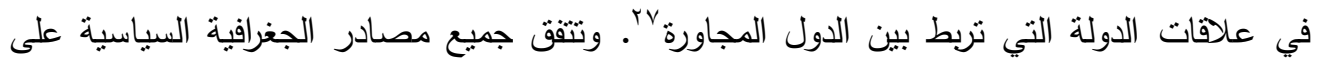

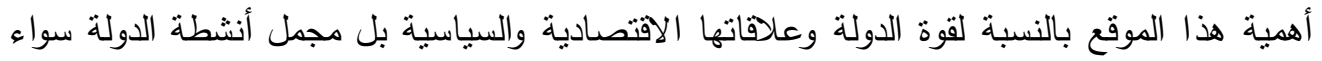

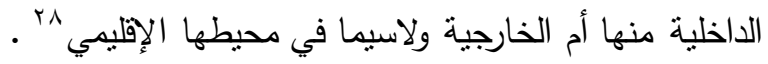

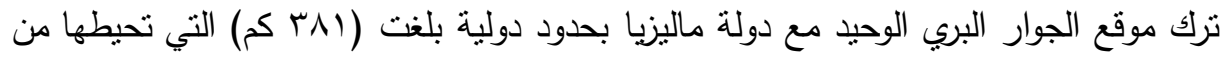

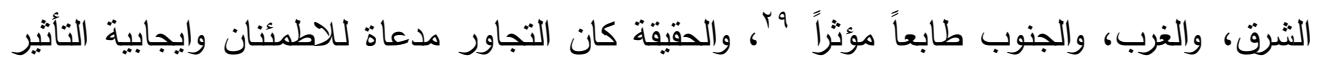

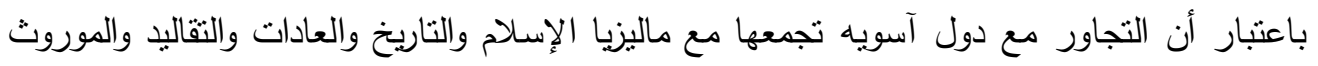

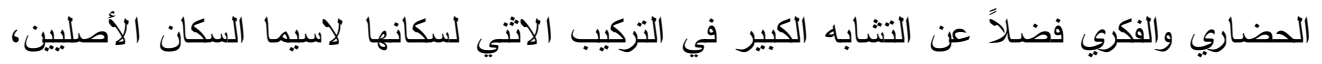

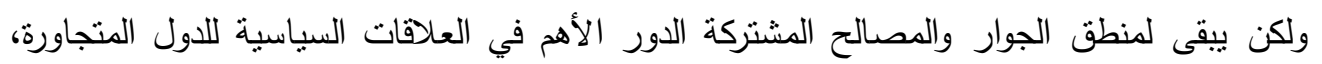
لتتعكس على الدول وسكانها واستقرار المنطقة اقتصادياً وسياسياً.

ثانياً: المساحة: The Area

ان الحجم او الحيز المساحي عامل مهم واساس في قوة الدولة او ضعفها، الا انه ليس

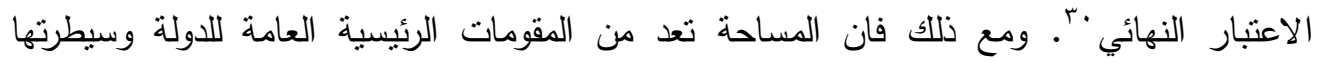

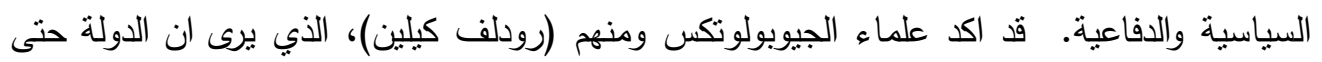

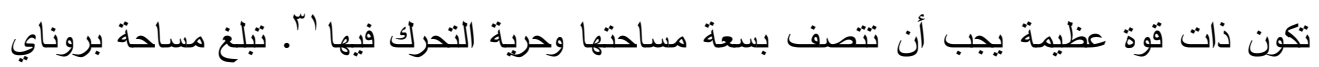

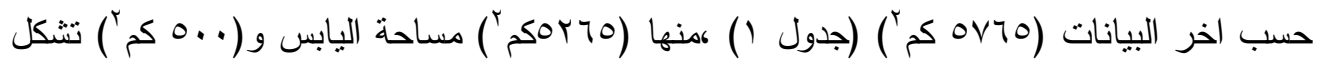

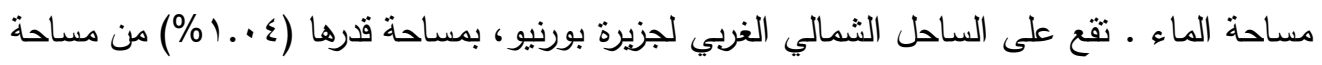

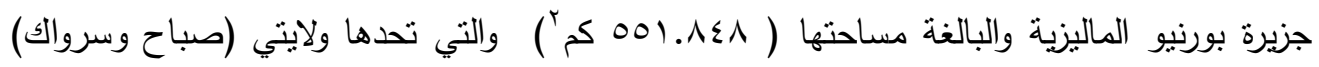

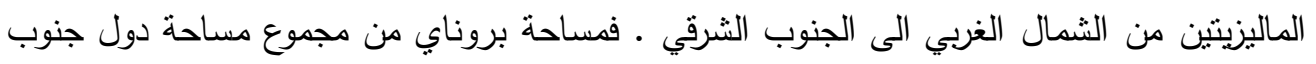

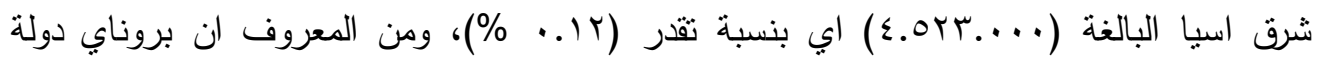


العدد الحادي والأربعون

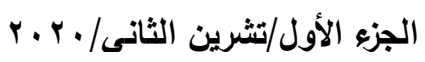

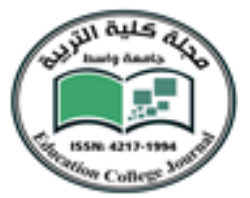

اسلامية فأنها تحتل نسبة (1.... (1\%) من مجموع مساحات دول العالم الاسلامية البالغة مساحتها

$$
\text { rr (r) (10.ro9) }
$$

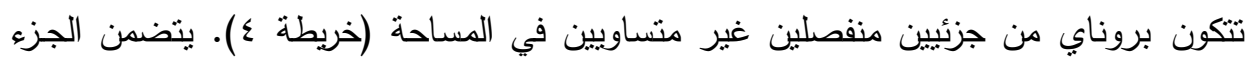

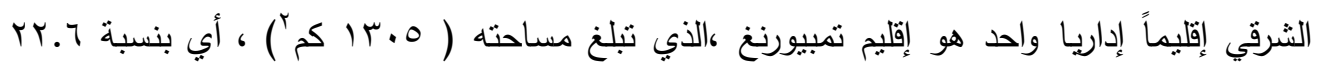

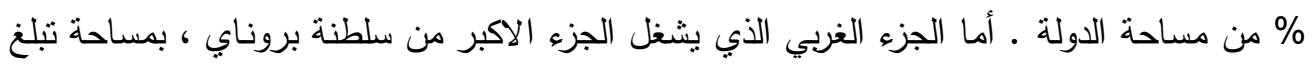

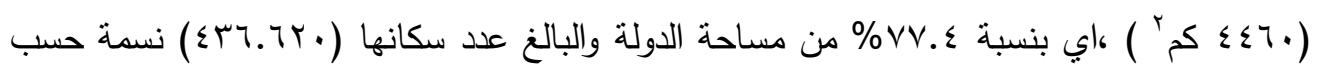

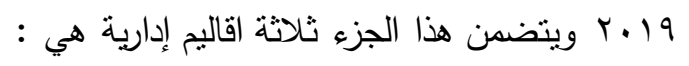

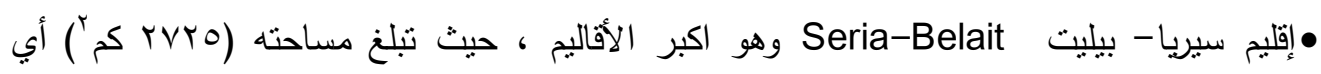
بنسبه \%₹ \% \% من مساحة السلطنة.

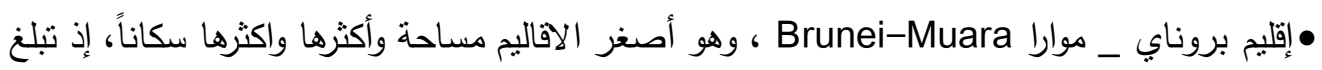

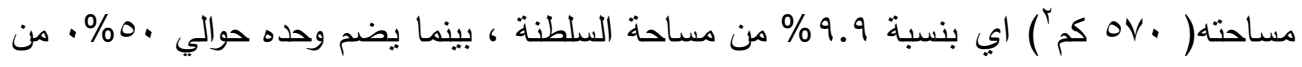

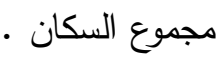

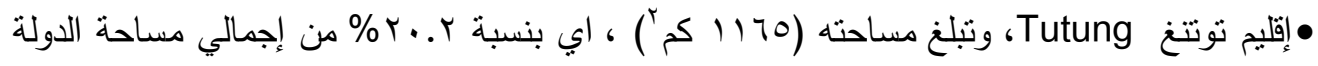

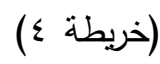

الاقاليم الادارية لسلطنة بروناي

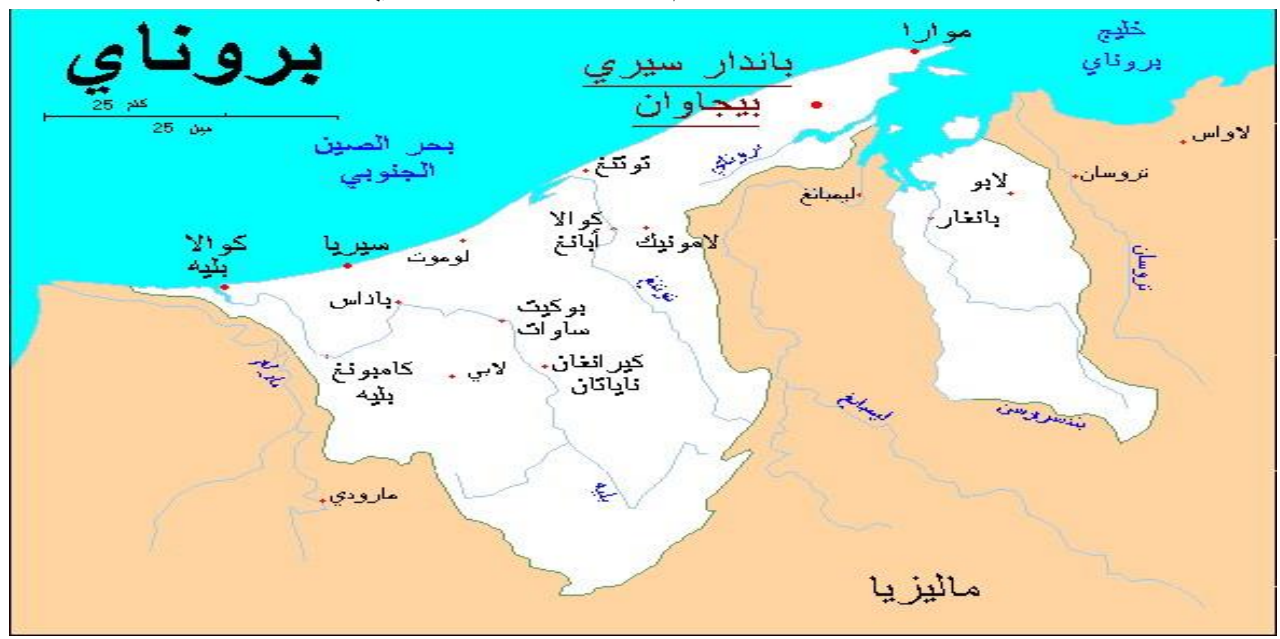

المصدر : الباحثة بالاعتماد

”URl:/http://www ويكيبيديا، الموسو عة الحرة, . Retrieved on Wed. 10, August, 2020. 
العدد الحادي والأربعون

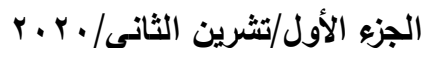

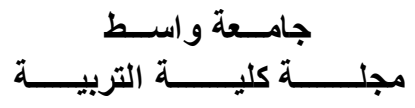

وهي بللك تصنف وفق تصنيف (هارم ديبليه Harm.J.de Blij) "*"*من الدول ذات المساحة

- الصغير

وعليه تتوقف المساحة المناسبة لأية دولة على العلاقة بين المساحة والسكان،. ورغم صغر مساحة

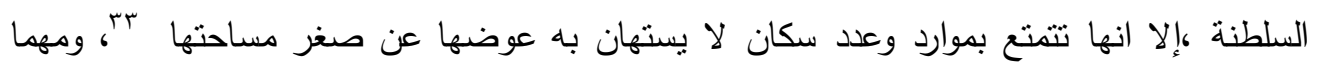

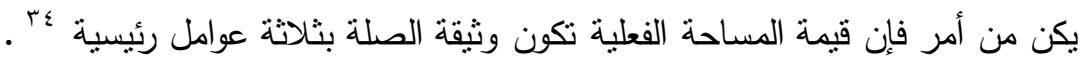

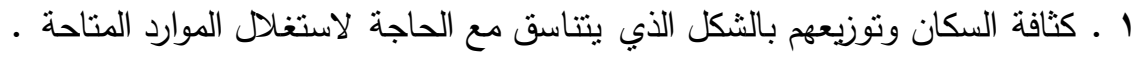
r r r حم الموارد الطبيعية وتتوعها وقدرة السكان في استغلالها اقتصادياً .

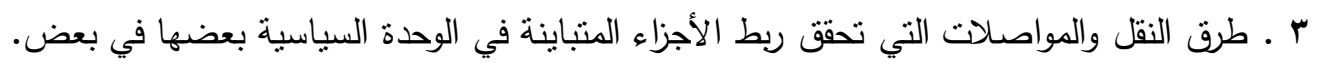

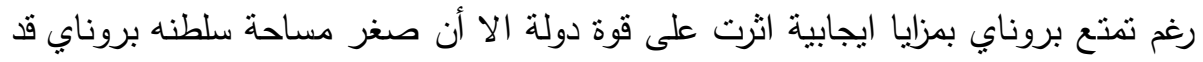

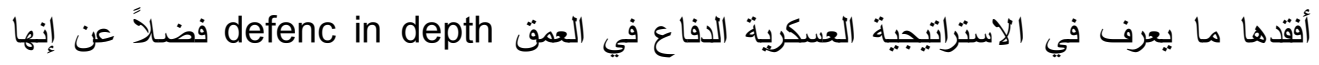

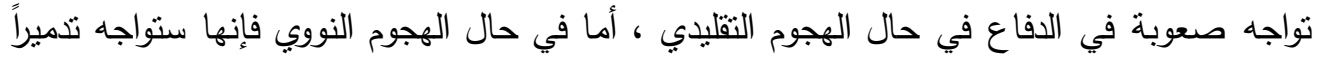

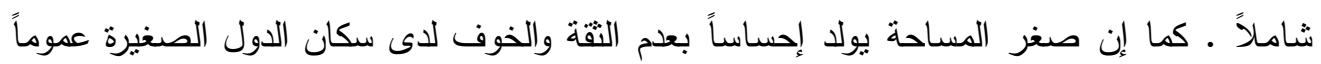

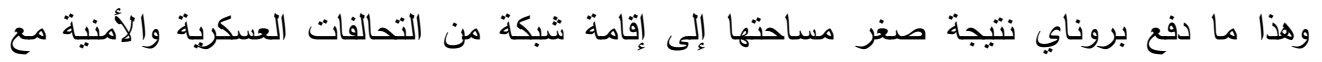
ماليزيا الدولة الوحيدة المجاورة لها وبعض الدول الافليمية كالفلبين وسنغافورة واندونيسيا وتايلاند

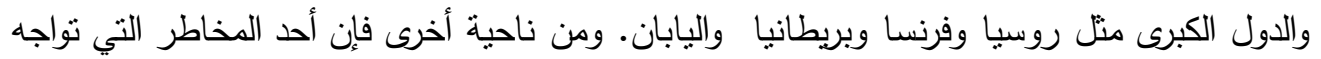
الدول الصغيرة الكوارث الطبيعية مثل الفيضانات وأعاصير التايفون " "*" الدمدرة .

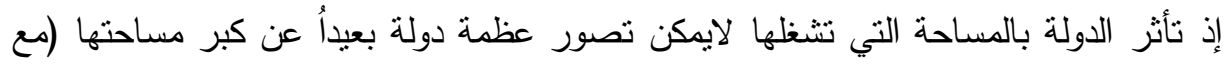

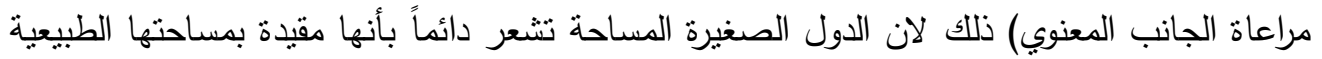

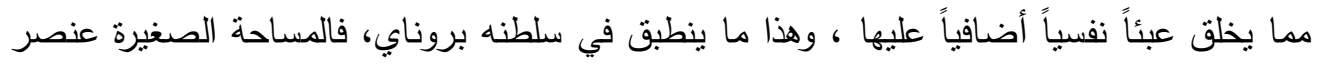

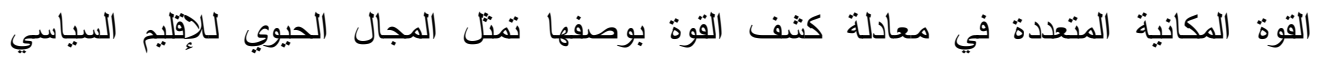

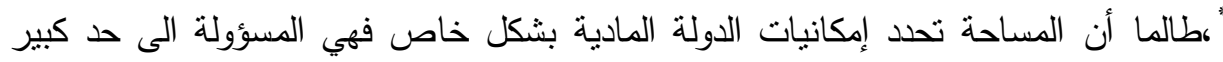

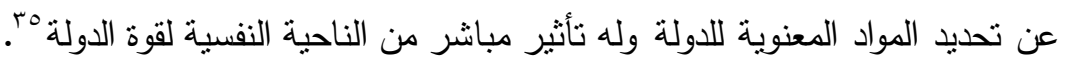


العدد الحادي والأربعون

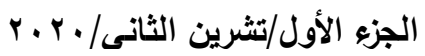

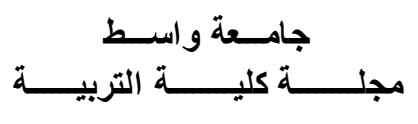

The Shape ثالثا: الثكل

يعبر شكل الدولة عن الترابط والتماسك بين أطراف الوحدة السياسية ، فالثكل الذي لا يكفل

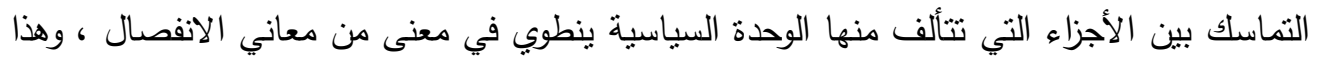

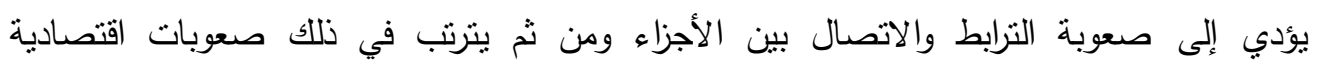

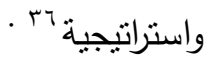

تتصف بروناي بأنها من الدول المزئة وهي أقرب ما تكون إلى الثكل المستطيل بجزيئه

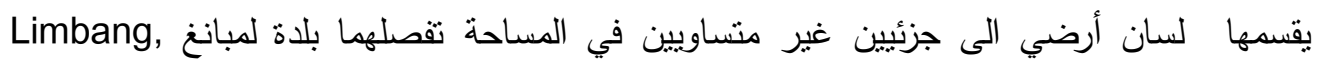

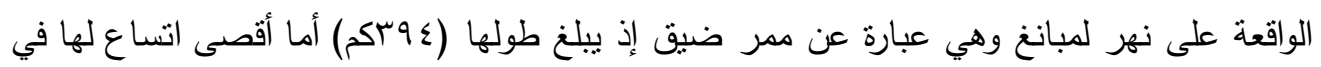

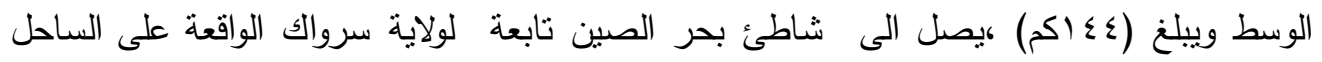

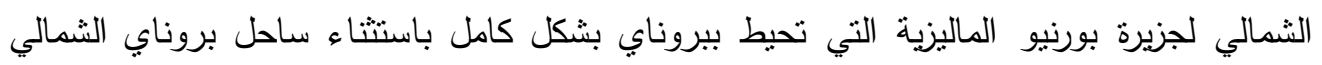
المطل على بحر الصبن الجنوبي. أن شكل سلطنة بروناب من ناحية الجغرافية السياسية، شكلا مجزئاً، بعني نقطة ضعف والتي

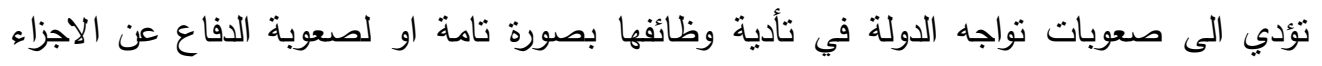

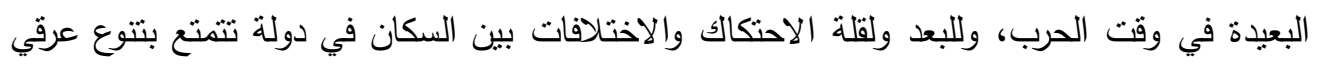

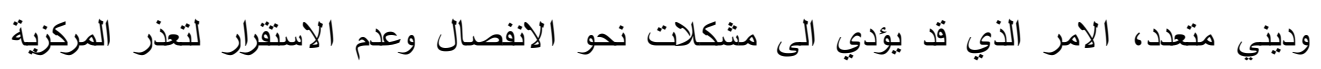

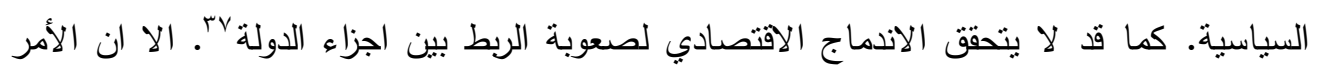

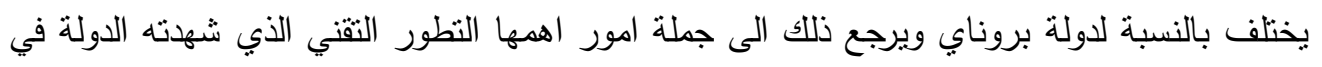

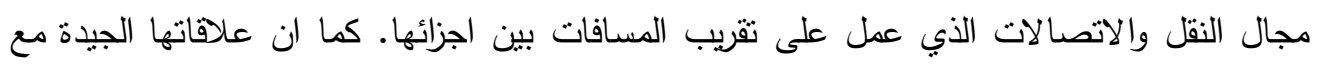

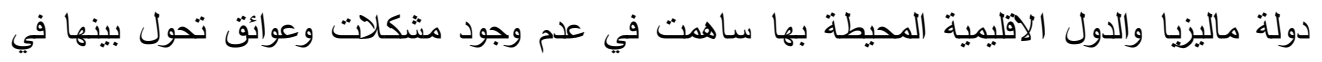

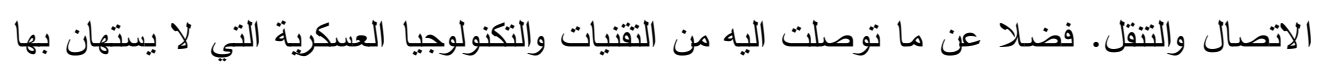
لاريء الخطر عنها. وترتبط بالموقع والمساحة والثكل موضوع العاصمة. فالموقع الاستراتيجي والهام لأي عاصمة

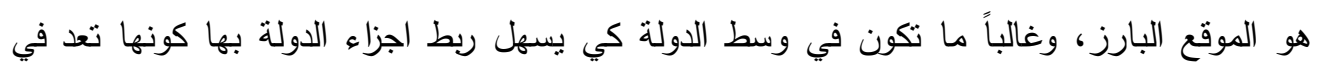

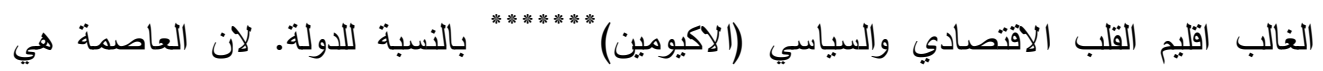
المدينة التي تسنقر فيها حكومة الدولة ورئاستها وسلطاتها وسفارات الدول الامنية والمؤسسات الكبيرة

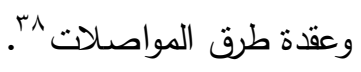


العدد الحادي والأربعون

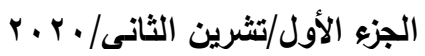

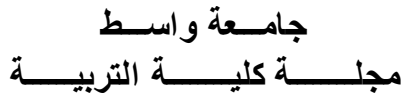

أما مركزية عاصمة سلطنه بروناي الحالية بالنسبة لسكان الدولة، فهي هامشية وليست

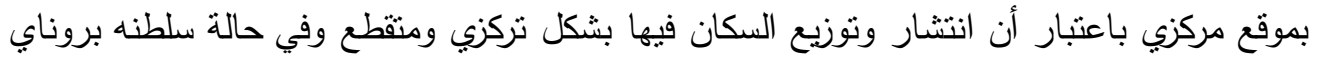

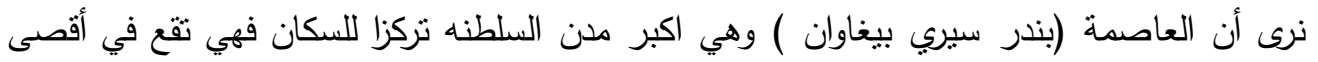

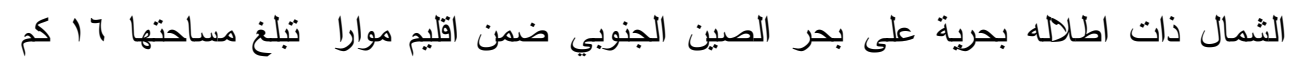
تقريباً، بينما تتركز كبريات المدن في الأطراف وبذلك فقدت عاصمة بحتئ بروناي مركزيتها الجغرافية والسكانية وبالتالي الأمنية والعكرية والسياسية، ما ترتب على ذلك ضعف أكيد الكيد ومؤثر في قوة السكان والدولة .

نستتنج مما سبق أن مساحة وشكل سلطنة بروناي تعد احد الجوانب الايجابية عند التقييم

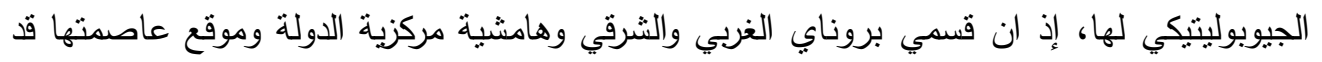

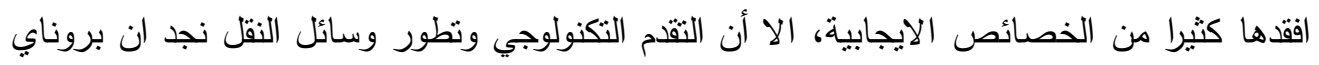

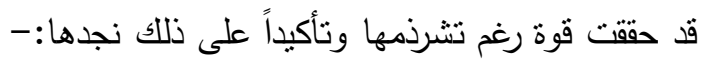

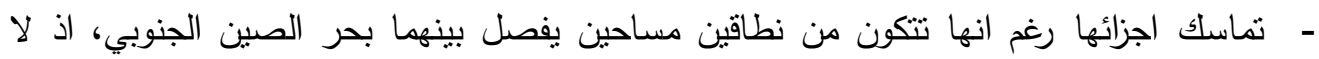
توجد اجزاء من اراضيها معزولة وراء دولة اخرى. - مد شبكات النقل والمواصلات وتوزيع مهام لجميع اطراف الدولة ساعد على حفظ الامن وسرعة دورة - الدفاع - خلق ذوع من التماسك الداخلي ساعد على تسهيل الاتصال بين المركز والاطراف وبين المراكز

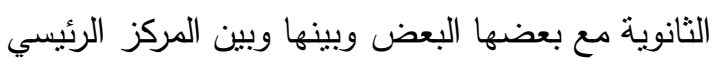
- ساعد شكلها المجزء الى مجاورة ولايتين (صباح وسيراواك) من دولة ماليزيا ذات النتوع الاثثي الثئي الذي يشابه الى حد كبير التركيب الاثثوغرافي لسلطنة بروناي.

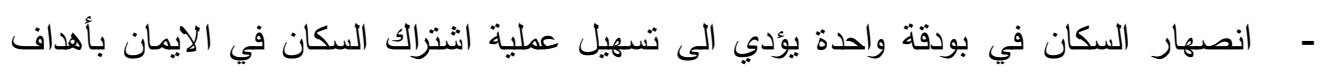

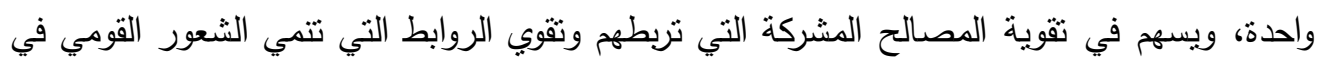
الدولة، وقد يصبح هذا الثعور المتأجج عاملاً حاسماً في رسم سياسة الدولة الدولة. رايعا: حدود سلطنة بروناي: The borders of the Sultanate of Brunei تتذاخل الحدود البرية بين سلطنة بروناب وماليزيا من الغرب الى الشرق بدءً من أنهار برغام

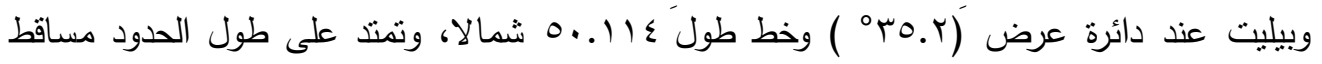

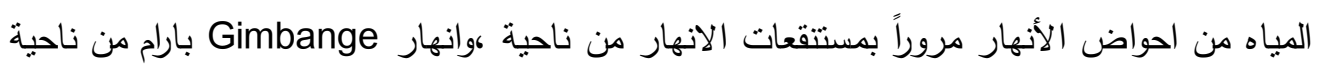

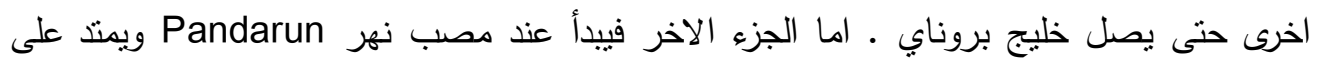


العدد الحادي والأربعون

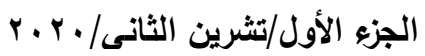

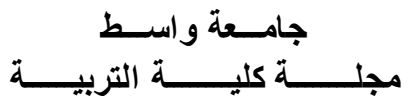

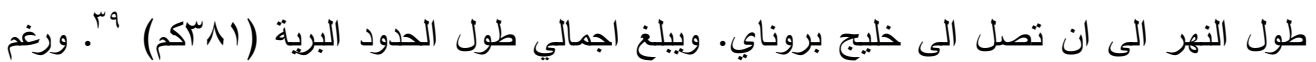
النزاعات الدائمة على الاراضي البرية الا ان العلاقات النقافية التي ترتبط بين الدولتين وققت حائلا

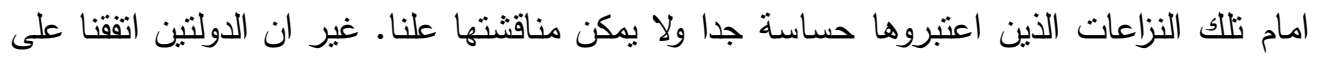
تسوية المشاكل الحدودية بينهما وترسيم حدودهم المشتركة وفقا للاتفاقيات الحسنة بطرق سلمية،

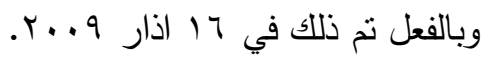

اما حدودها البحرية فقد ورثت بروناي من ماليزيا حدود بحرية في سراواك وبورينو الشمالية وفق نظام مجلس الحدود العام الاستعماري، حيث استعيدت بريطانيا ثلاثة قطاعات لصالح بروناي أ- القطاع الثرقي من سراواك حتى خليج بروناي. ب- القطاع الغربي تتمنل في الحدود الغربية مع بروناي اتجاه البحر .

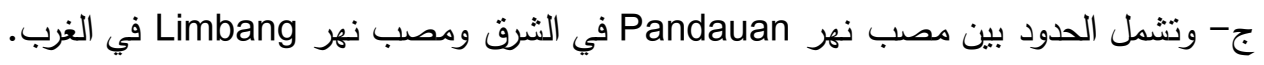
اما المطالبة بالجرف القاري والتي تعتبر منطقة اقتصادية نشتمل على جزر سبرانلي وبحر الصين الجذوبي والجزر المرجانية فلازالت تحنلها ماليزيا وهناك مفاوضات سلمية لازالت مستمرة بينهما ' بامين

خامسا: البنية الجيولوجية والتضاريس The Geological Structure and Topography

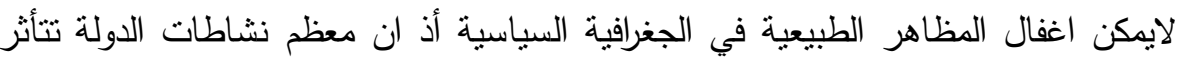

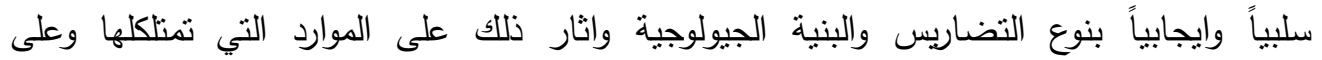
طبوغرافيها، فهو يصرف مياهها، كما ويوجه خطوط المواصلات والنقل، وعلى هذا النحو تماما يمكن

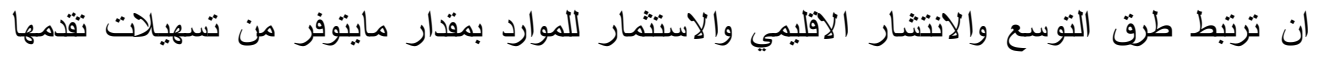

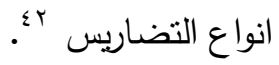
أن للتضاريس الأرضية اعتبارات كبيرة في الجغرافية السياسية وتكاد لا تخلو مصادرها من

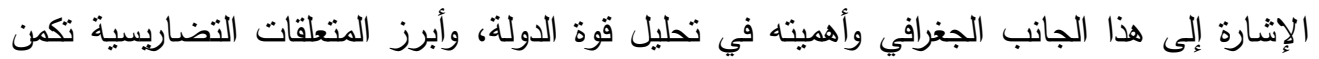

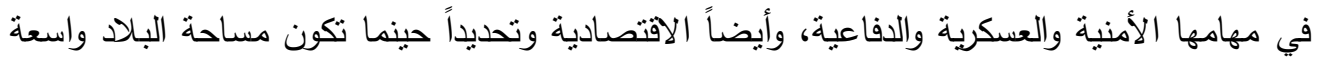

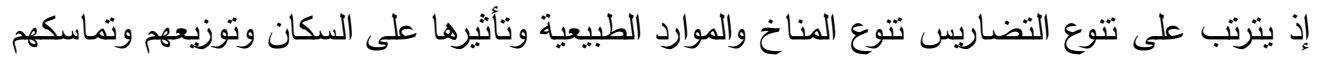

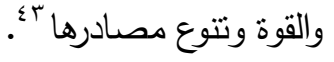

وعليه لابد من معرفة جيولوجية المنطقة باعنبارها جزءاً مهما من طبوغرافية منطقة الدراسة

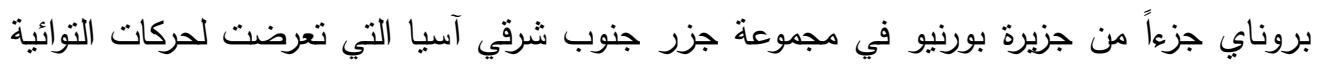


العدد الحادي والأربعون

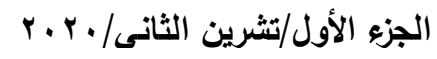

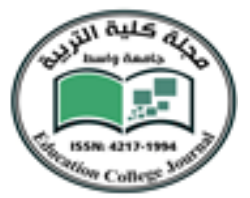

في الحقب الثاني، وهي إحدى جزر مجموعة السوندا الكبرى في جنوب شرق آسيا، التي تتنمي بدورها

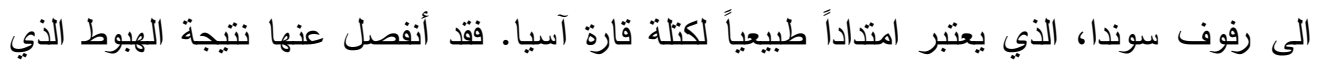

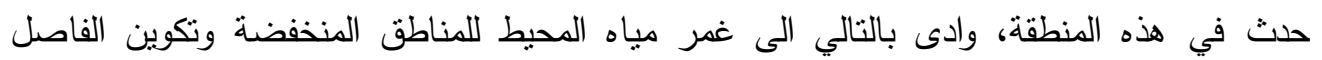
المائي المتمثل في بحر الصين الجنوبي. ومن ثم فإن البنية الجيولوجية لبروناي تتكون أساساً من البناه

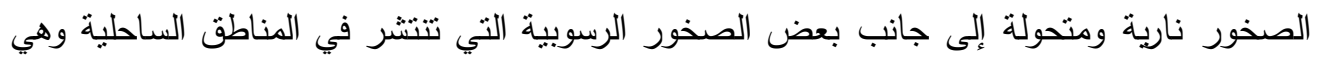
في معظمها صخور جيرية ورملية . كما تتوعت المظاهر التضاريسية لدولة بروناي ما بين الجبال والسهول الساحلية ونتوءات

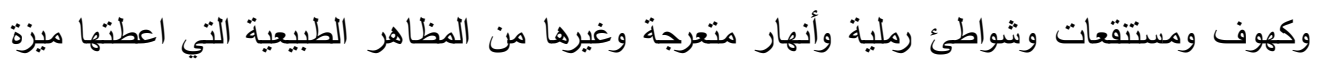
طبيعية منفردة وتتبع معالم التضاريس الارضية لدولة بروناب على النحو التالي :

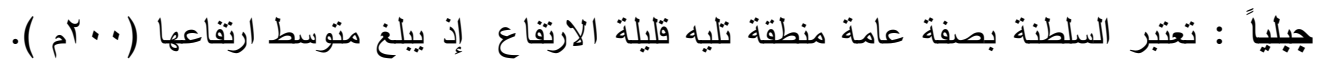

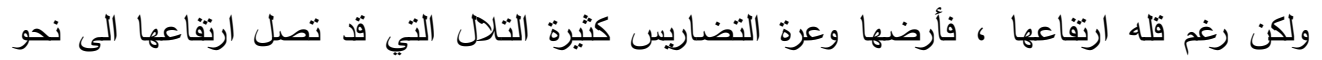

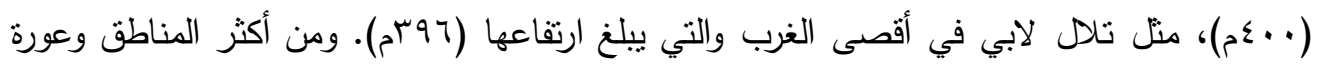

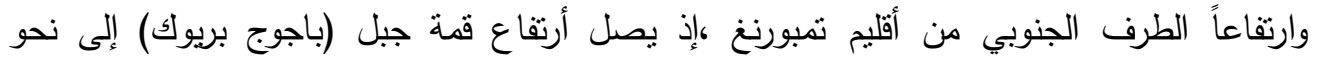

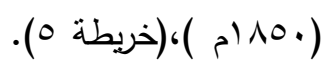

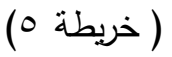

تضاريس سطح بروناي

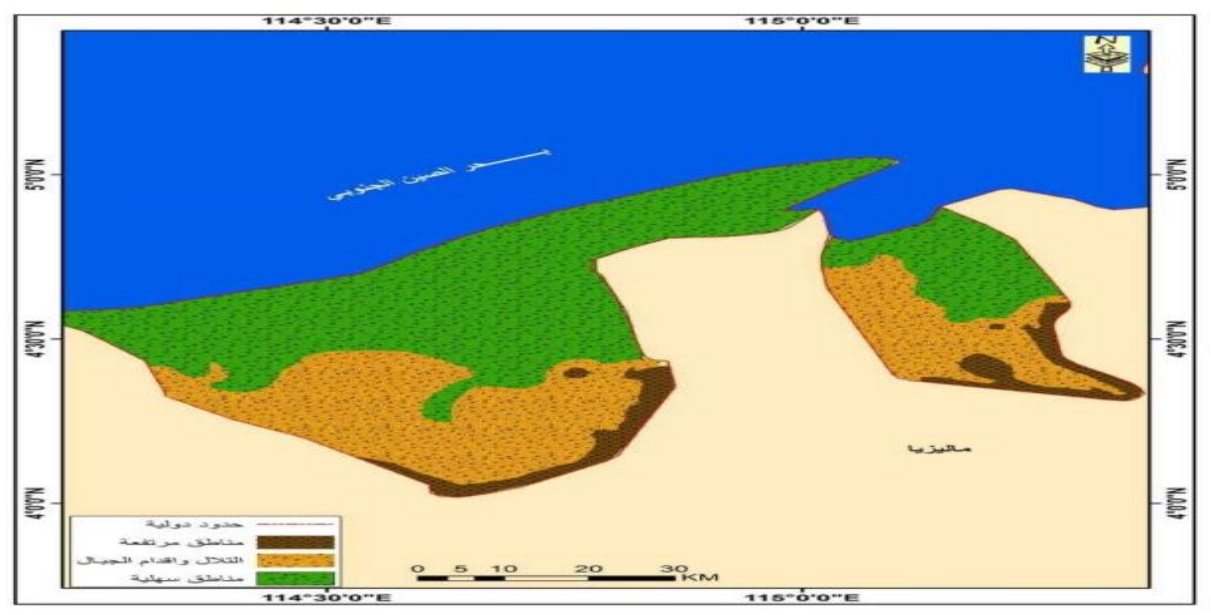

المصدر : الباحثة بالاعتماد على الم

- Concise Atlas of the World, Collins Publishers, London,2010,p.116. 
العدد الحادي والأربعون

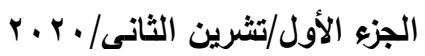

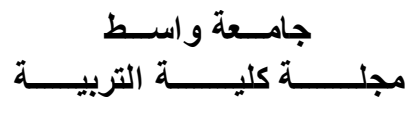

انهارها: يجري على أرض بروناي العديد من المجاري المائية الني تتبع من المرتفعات الواقعة في

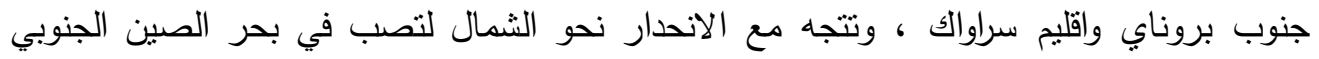

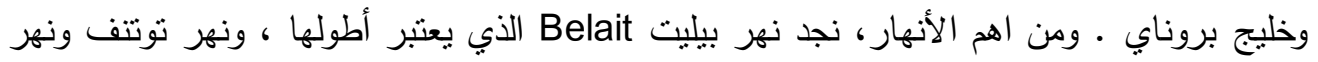

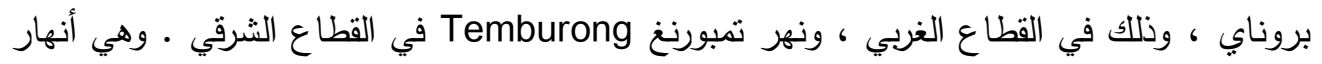

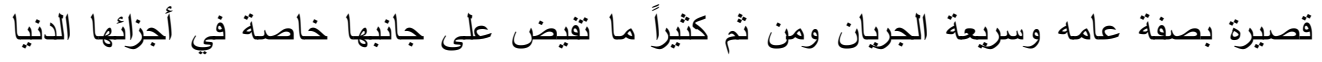

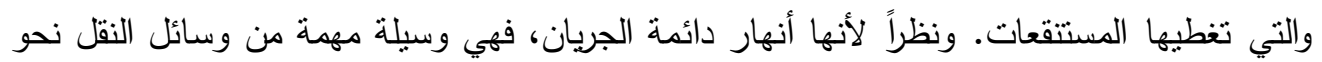

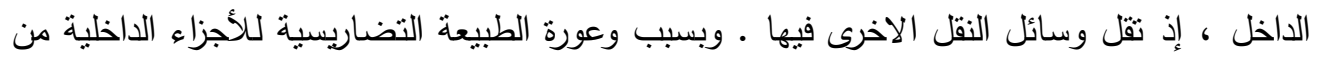
الدولة فقد نركزت محاور استقرار السكان وشبكة طرق النقل بالدرجة الاولى في المناطق المنخفضة .

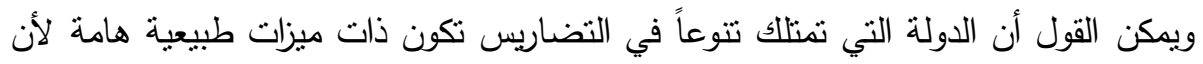

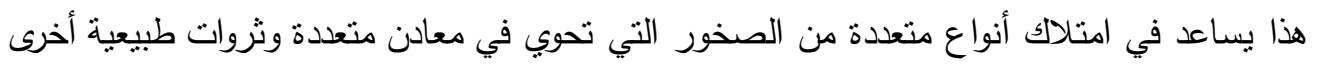

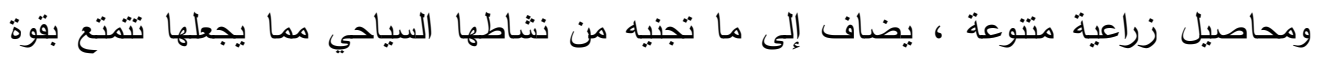

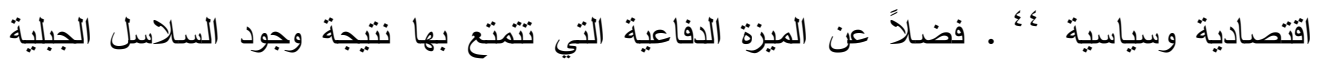

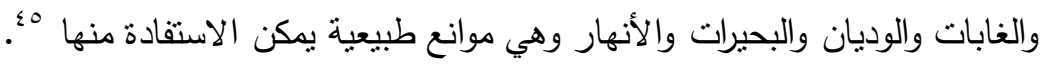

Climate سادساً: المناخ

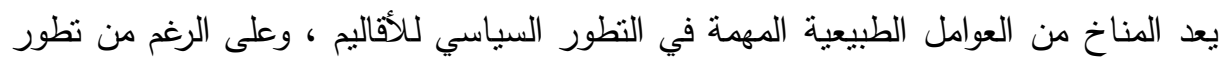

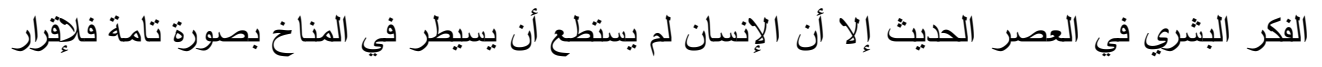

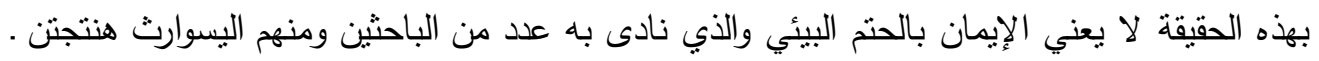

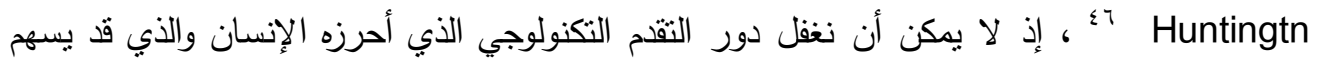
في تقليل دور العوامل المناخية . في ضوء الموقع الفكي، تقع بروناي داخل نطاق المناخ المداري المطير ((الاستوائي البحري))

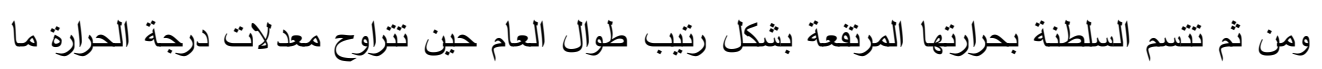

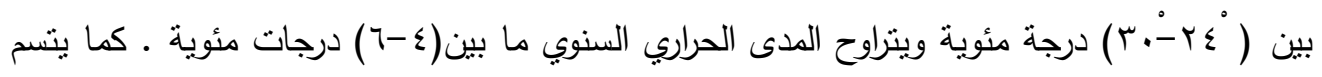

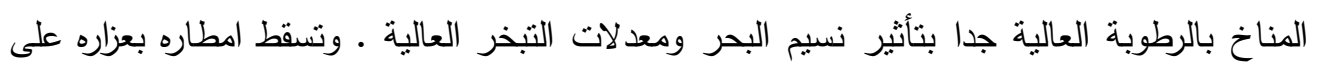

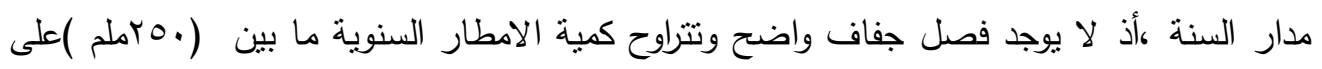

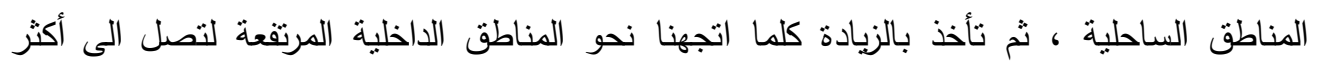


العدد الحادي والأربعون

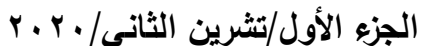

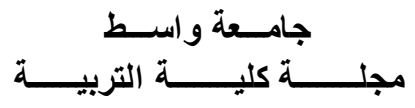

من( · م. ملم ، وتتأثز بروناي كمية الامطار الساقطة بالرياح الموسمية الثمالية الشرقية المصحوبة

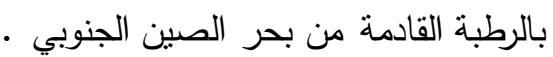
على رغم من أن الامطار الغزيرة مفيدة في توفير مورد مائي كبير، إلا أنها قد تسبب في حدوث

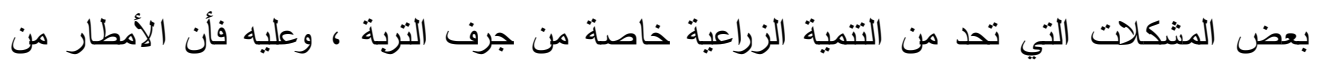

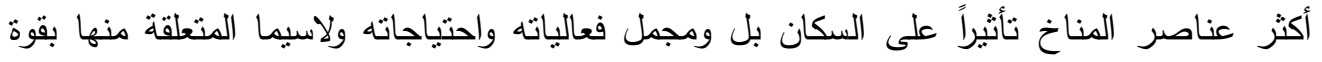

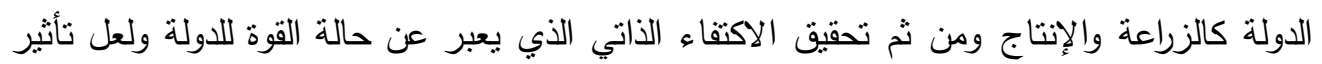

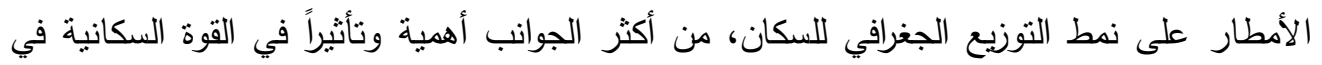

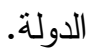

يتضـح مهـا تقدم ان كميـة الامطار الكبيرة التي تسقط على سطح سلطنه برونـاي تستغل

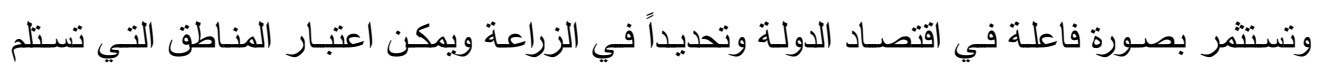
كميات اكثر من( . . ملم) وخاصـة الداخلية كنها لدعم الحياة النباتيـة والحيوانيـة ، والتي لها مردوداً ايجابياً على اقتصاد الدولة.

Natural Resources سابعا: الموارد الطبيعية

تشير معظم مصادر الجغرافية السياسية والعلاقات السياسية الدولية. الى أن الموارد الطبيعية

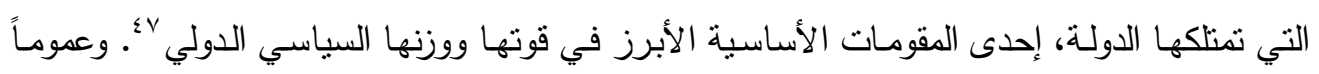

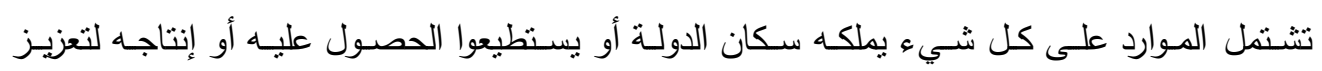

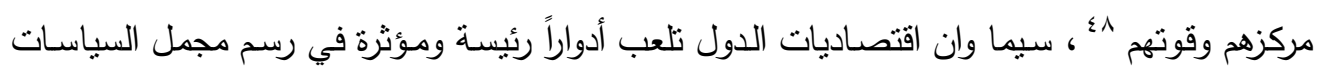
العالمية الحالية والمستقبلية.

أن للسكان الدور الأساسي والمحوري في تفعيل أهمية موارد الدولة الطبيعية، فوجودها لا يعني

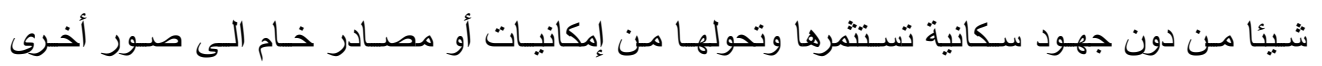

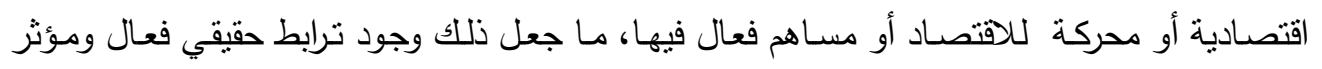

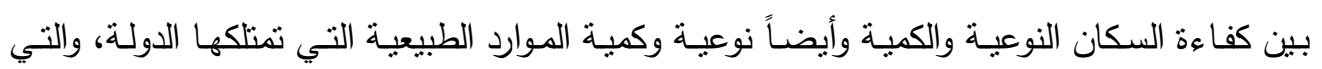

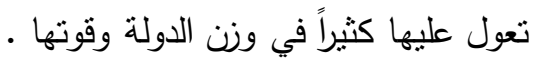

يقتصر بحثنا للموارد الطبيعية لسلطنه بروناي على الموارد الاتية باعتبارها مؤثره في قوة الدولة :

1 - النبات الطبيعي (الغابات). Natural Vegetation(Forests)

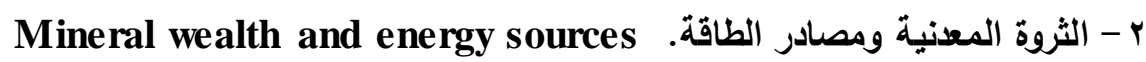


العدد الحادي والأربعون

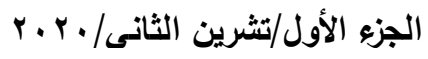

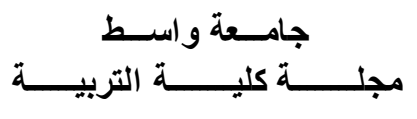

1 - لنبات الطبيعي (الغابات). Natural Vegetation (Forests)

تعتبر الغابات الطبيعية المظهر النباتي العام لسلطنه بروناي وتحتل نسبة كبيرة من مساحة

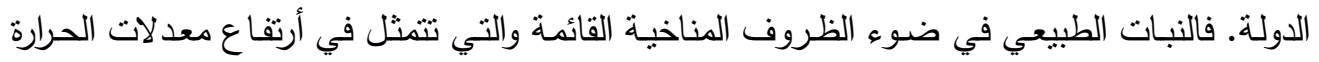
والرطوبة على مدار السنه ، فان الغابات الددارية المطيرة "الاستوائية " تعتبر الصورة النباتية السائدة

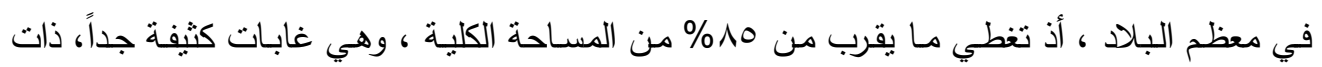

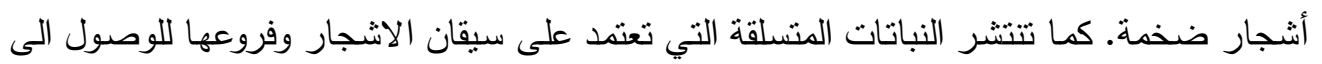

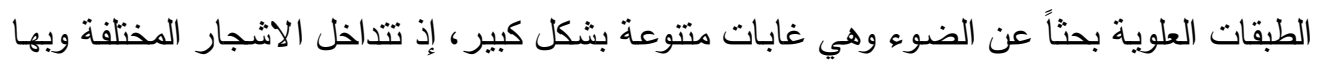

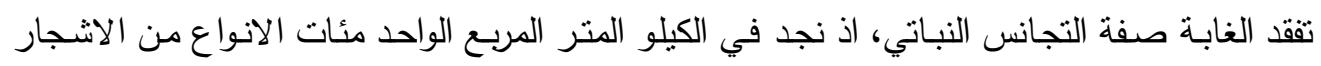

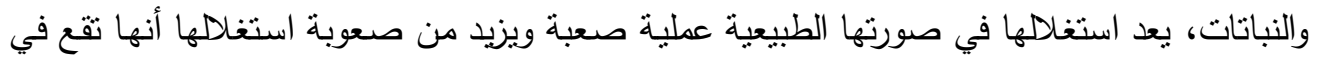
مناطق وعرة التضاريس صعبة الوصول اليها ومن ثم فهي لاتزال بكر محتفظة بصورتها الطبيعية في

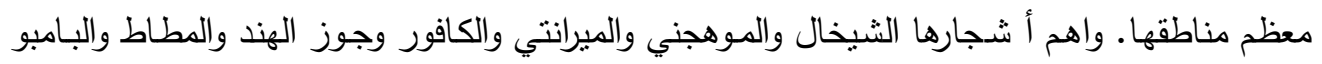

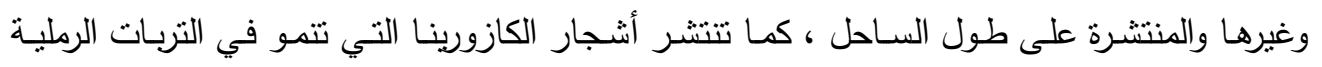

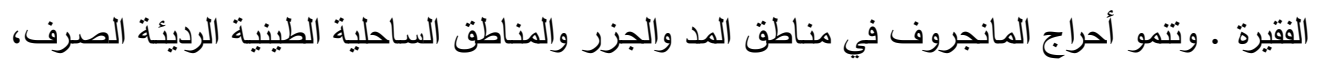

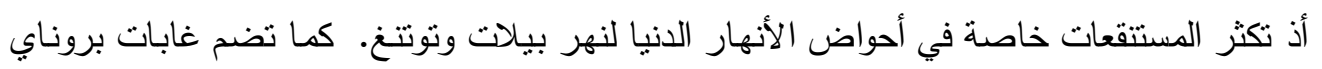

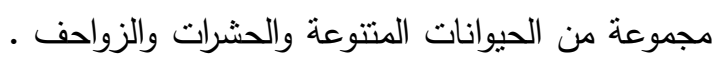

تعرضت الغابات الددارية المطيرة في بعض مناطق الدولة للقطع والحرق من آجل الزبرات ولرواعة

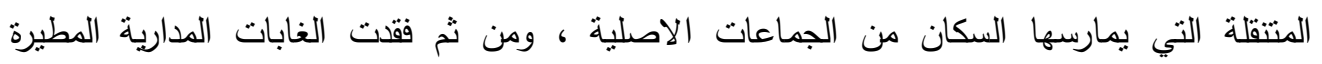

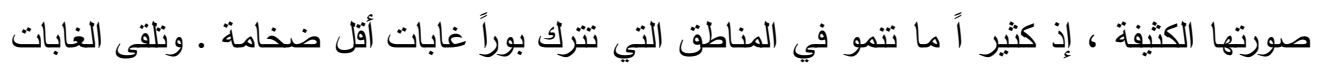

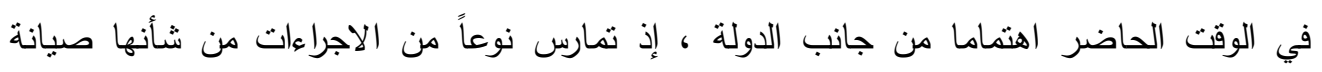
الغابات وتتميتها ـ بدات الدولة تضع فقرة خاصة تتضمن زيادة ونتمية مساحات الغابات الددارية

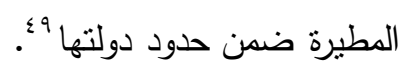

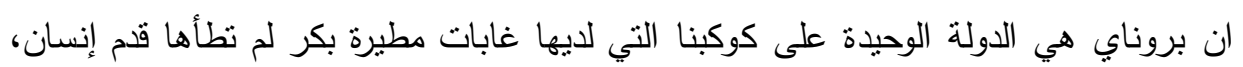

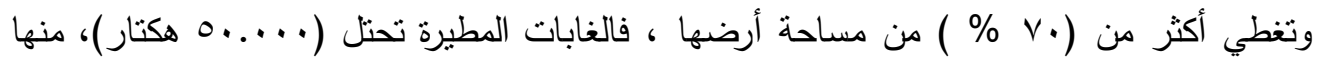
بعض أفضل المحميات الطبيعية في آسيا. ويتجسد ذلك في حديقة أولو تنمبيرونغ الوطنية الني تعتبر واحدة من أكثر الوجهات السياحية شهرة في برونايز 
العدد الحادي والأربعون

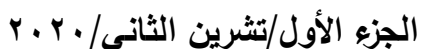

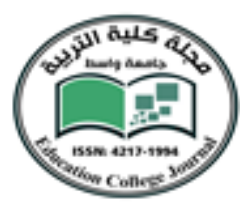

با ب الموارد المعنية ومصادر الطاقة. Minerals Resource and energy sources يعتبر النشاط التعديني أهم الأنشطة الاقتصادية أذ امتلاك الدولة للثروة المعدنية له اثر كبير في تقدمها وتطورها، هذا فضلا عن أثرها في قوة الدولة واستراتيجيتها. وعلى الرغم من محدودية كميتها

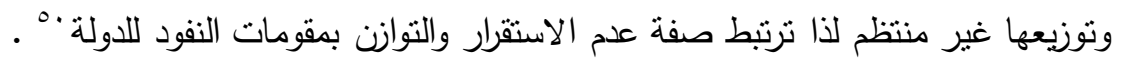
وتمنلك برونـاي مساحة جيولوجية غنيـة بالنفط والغاز الطبيعي والمعادن الاخرى ذات الاهمية الاستراتيجية في بناء القوة الذاتية للدولة بعد الكثوفات التي تبنتها الدولة الاستعمارية المتعاقبة عليها

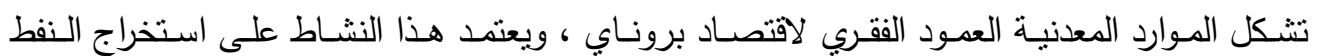
والغاز الطبيعي وعلى النحو التالي: (خريطة ؟ج).

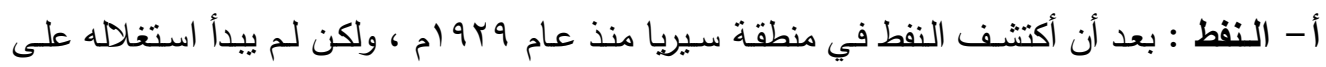

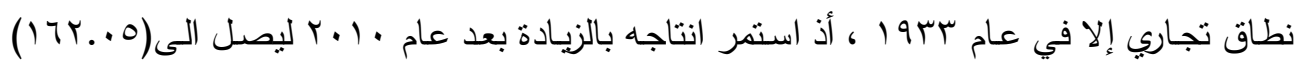

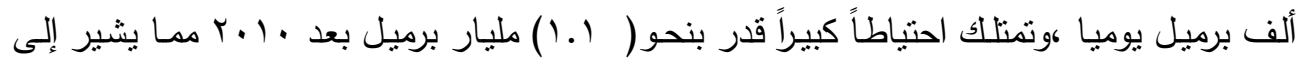

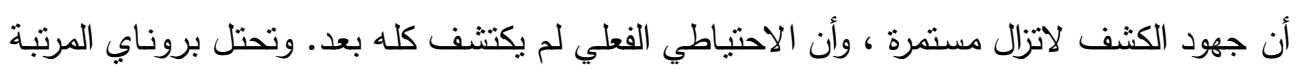

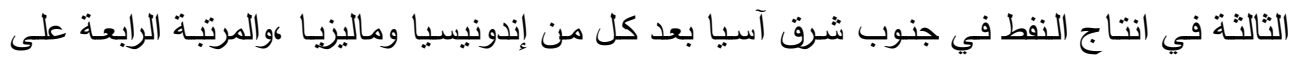

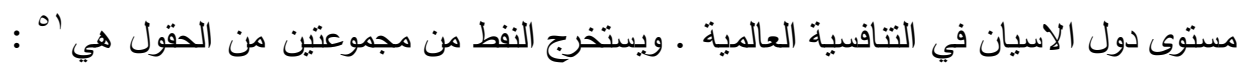

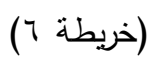
حقول النفط والغاز الطبيعي في سلطنة بروناي

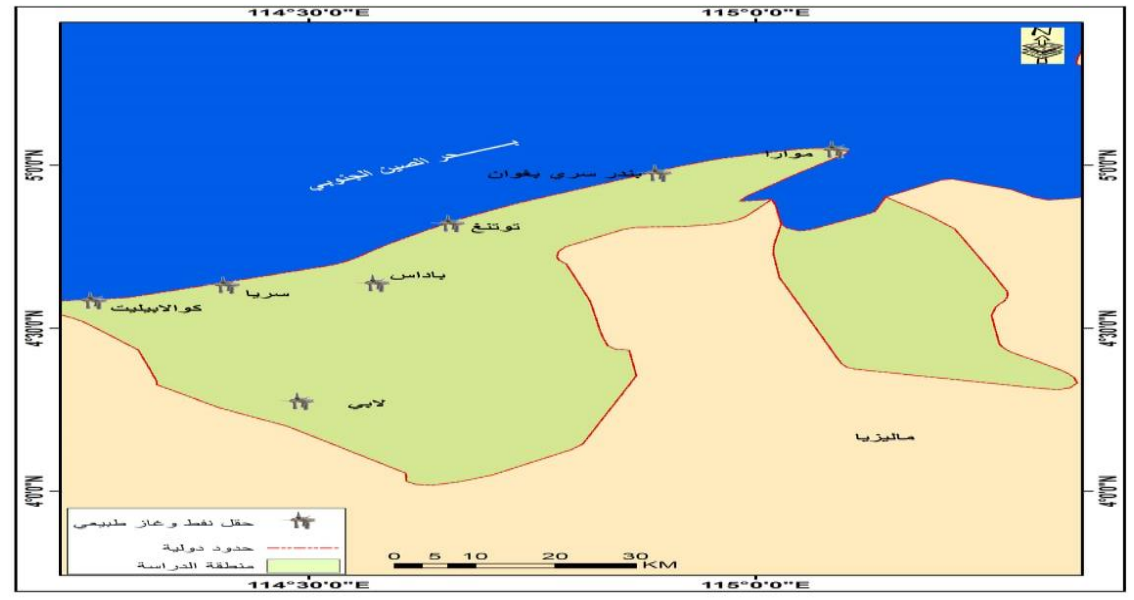

المصدر : الباحثة بالاعتماد على - الم

Concise Atlas of the World, Collins Publishers, London,2010,p .116. 
العدد الحادي والأربعون

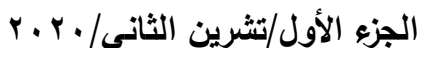

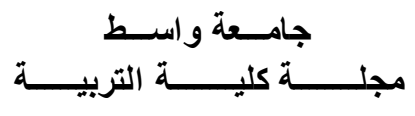

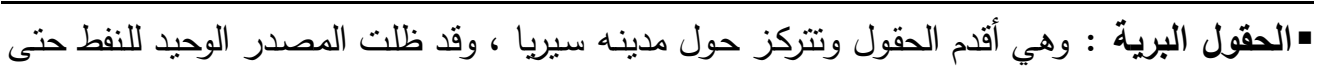

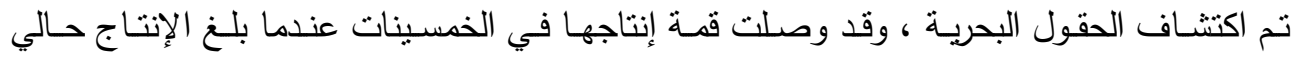

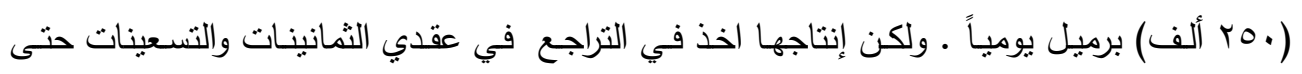

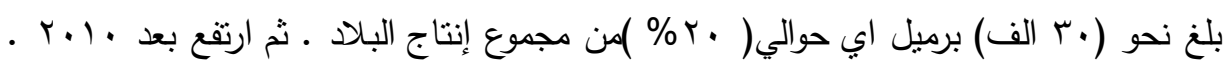

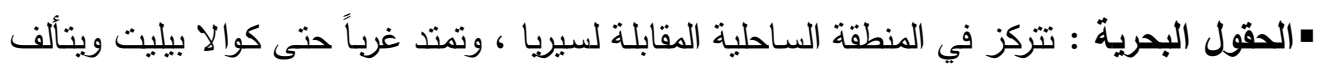
من خمسة حقول هي (شامبيون، ماجبي، جنوب غرب أمبا، فيرلي، وفيرلي بارام) • وتعتبر الحقول

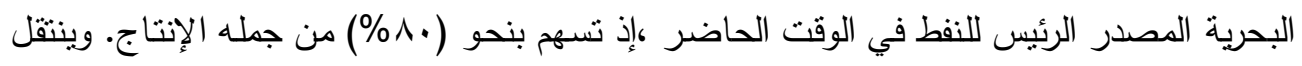

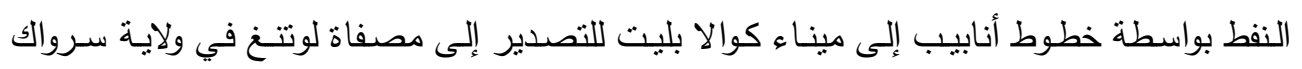
للتكرير

تولى إنتاج النفط شركه شل بروناي ، التي تمنلك الحكومة (00\% ) من إسهامها. وتثبير النقارير أن

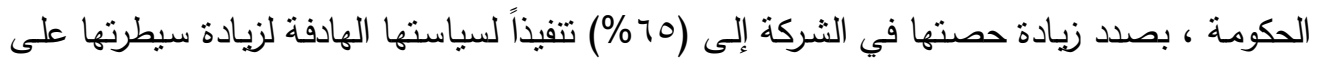

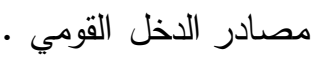

يستهلك جزء محدود جداً من الانتاج محلياً لا يتعدى ^٪ و ويصدر الباقي للخارج ، عمـاً ان

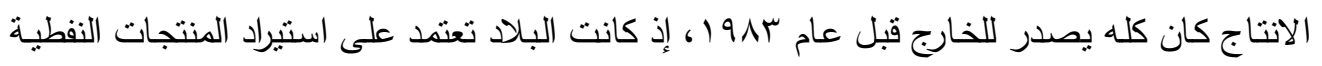

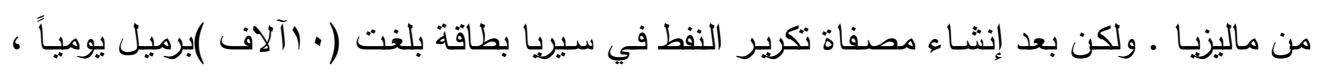

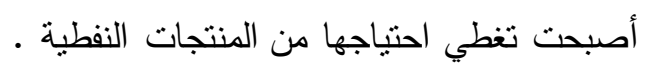
لازالت بروناي تقوم بجهود مسحية كبيرة لاستكمال حجم الاحتياطي الاجمالي المتوفر في البلاد

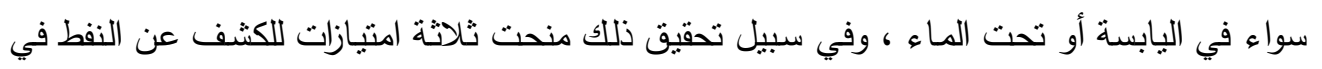

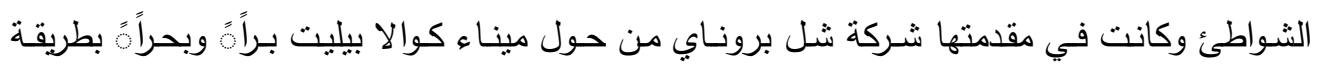

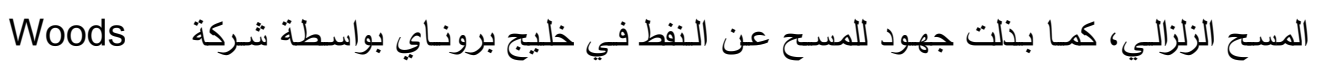
أضافه Petroleum Corporation

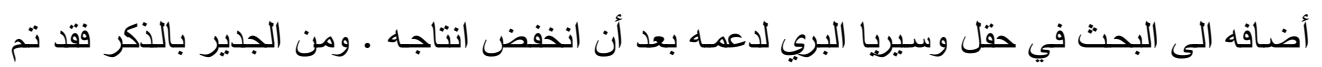

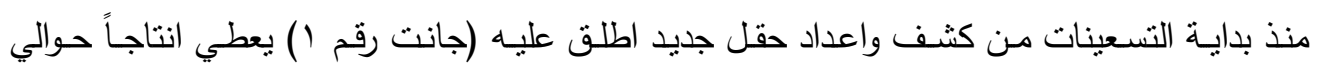

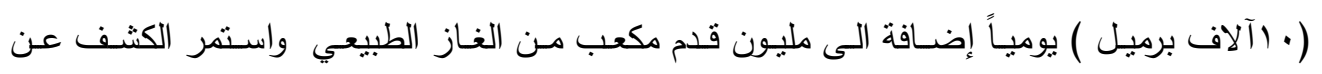

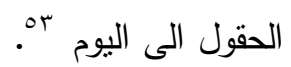


العدد الحادي والأربعون

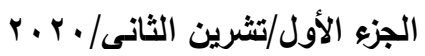

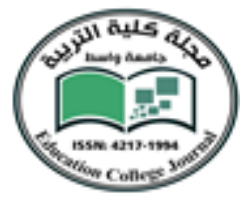

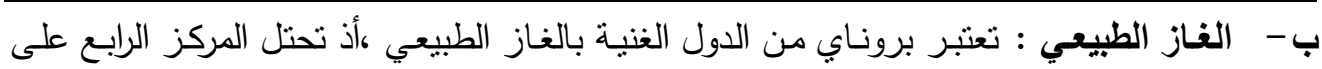

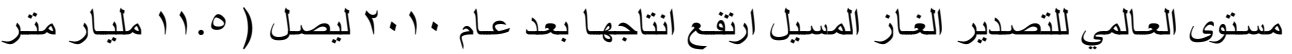

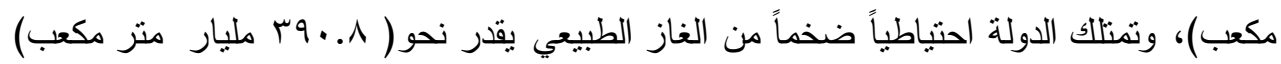

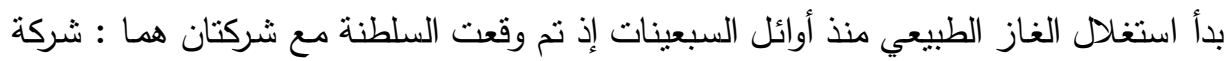
بروناي لتسيل الغاز وشركه بروناي للغاز المبرد ، حيث يقومان بتسييل الغاز وتسويقه بنسبة بro

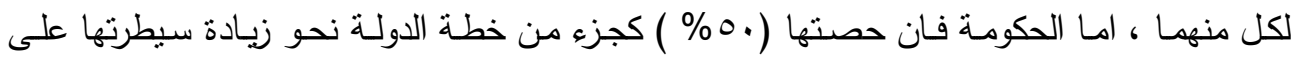

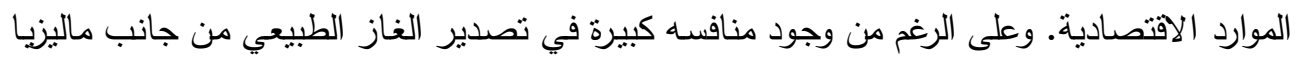

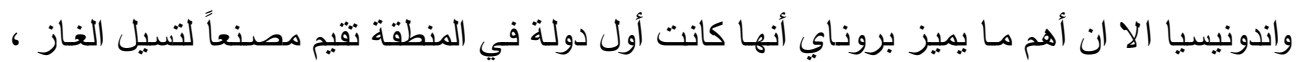

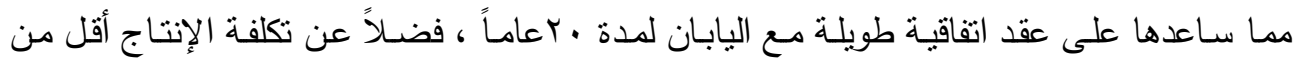
مثيلاتها في كل من ماليزيا واندونيسيا.

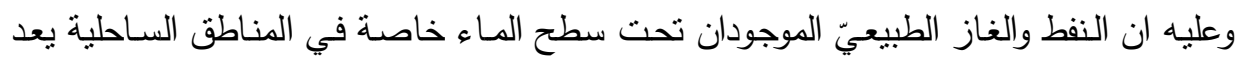

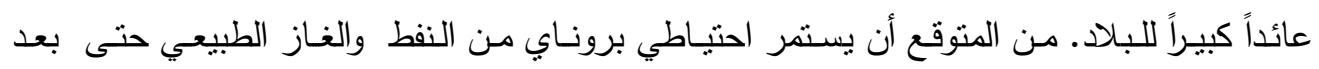

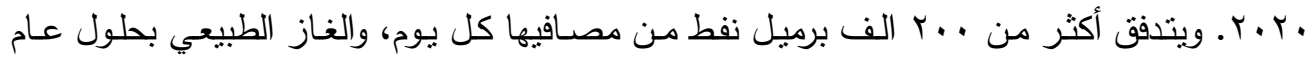

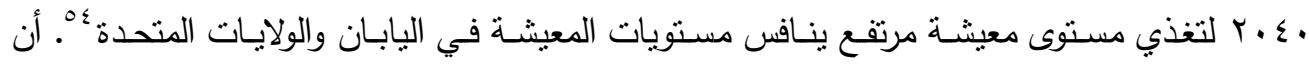

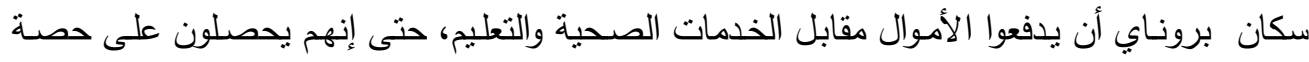
الفرد من إجمالي الناتج القومي من دون أية ضرائب.

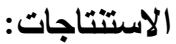

1-بعد الاستكثافات الجغرافية اصبحت بروناي محط انظار الاستعمار الدولي والاقليمي التي تعاقبت

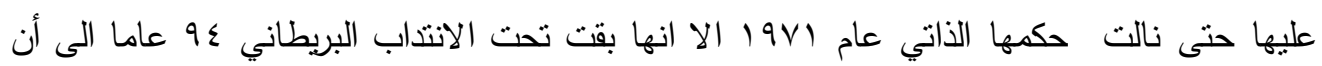

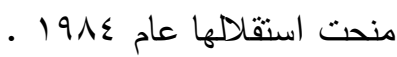
r-تغلبت بروناي بتتوع تضاريسها التي اثر على تتوع مناخاتها وبيئاتها التي عوضها على صغر

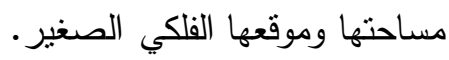
r-تمكنت بروناي بحكم موقعها من اليابس والماء تحديد علاقتها ووظيفتها الرئيسية مع الدول سواء الدولية منها او الإلمية سياسيا واقتصاديا واجتماعيا. ع -أن الساحل البروناوي اكتسب أهيته كونه منطقة التركز السكاني، وموقعاً استراتيجيا لظهور النفط والغاز المسيل والمعادن الأخرى أثرها الكبير لتحدد جانباً من تتامي أهمية الموقع. 


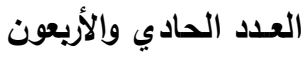

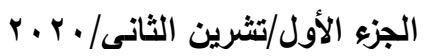

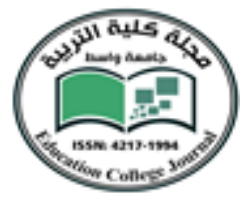

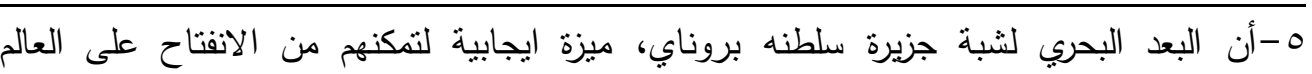

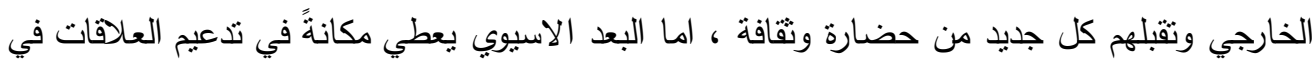
جنوب شرق آسيا منها الجوار الماليزي المشترك معها في الحدود والتركيب الاثثوغرافي والموروث

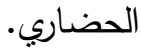
1- أن التقام التكنولوجي وتطور وسائل النقل وتماسك اجزائها الني شهدته بروناي قد حققت قوة رغم تشرذمها مساحةً وشكلاً ، لذا فهي تعد أحد الجوانب الايجابية عند التقييم الجيوبوليتيكي لها.

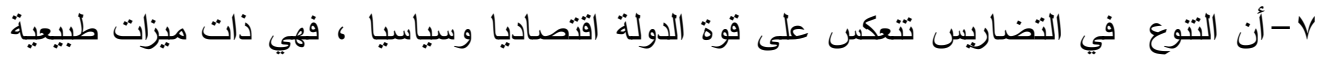

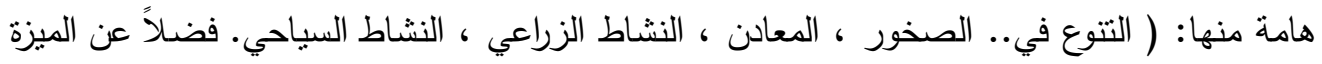

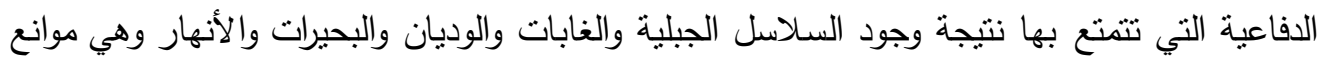
طبيعية بمكن الاستفادة منها. ^-ان المردود الاقتصادي الكبير لسلطنة بروناي نجم عن الكميات الأمطار لكبيرة التي تسقط عليها

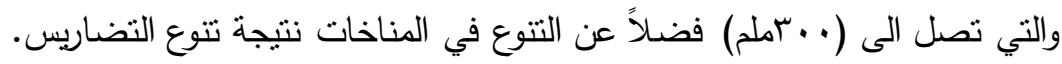

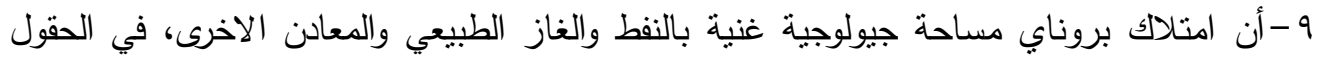
البرية والموجودة تحت سطح الماء خاصة في المناطق الساحلية المنتج منها والاحتباطي يعد عائداً كبيراً للبلاد. • ا- ان بروناي هي الدولة الوحيدة على كوكبنا التي لديها ثروة غابية بكر لم تطأها قلم إنسان، وتغطي أكثر من ( V \% \% من مساحة أرضها.

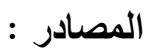

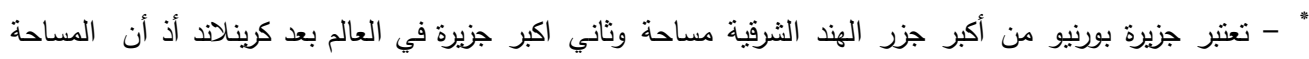

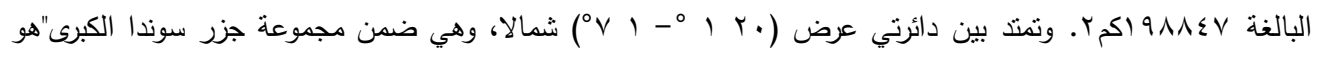

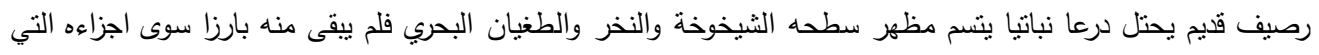

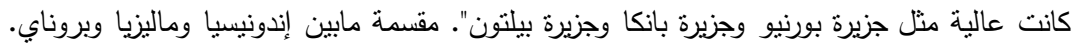

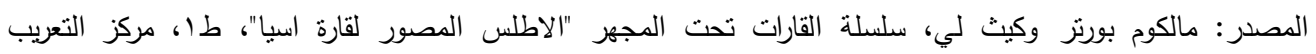

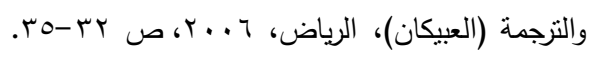

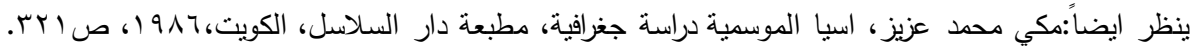

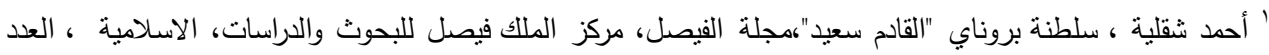


العدد الحادي والأربعون

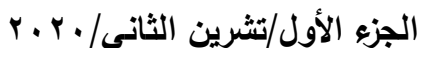

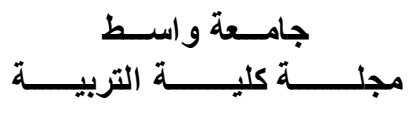

${ }^{2}$ Johannes L. (2006). Kurz 'Kurz' Boni in Chinese Sources: Translations of Relevant Texts from the Qing Dynasties'. Retrieved from http;//www.ari.nus.edu.sg/article_view.asp?id=172.

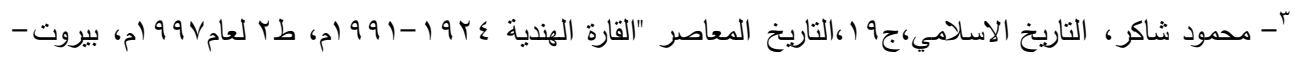

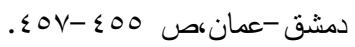

؛ - اسماعيل احمد ياغي، محمود شاكر، تاريخ العالم الاسلامي الحديث والمعاصر

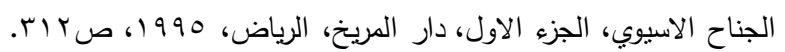

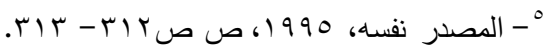

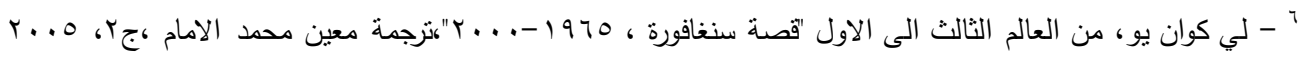

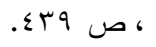
ينظر ايضاً:

- Gordon P. Means and Gordon P. Means.(1976). Malaysian Politics. Singapore: Choong Moh and Company. Second Edition,P. 305.

7 -Kevin Y. Tan. (2011). International Law, History and Policy: Singapore in the Early Years. Singapore: Center for International Law. ,PP.10.

^ -عبد الكريم حسين الثباني ويعرب عبد الرزاق الدراجيهدور نتكو عبد الرحمن ف تشكيل ماليزيا عام باجو (،مجلة كلية

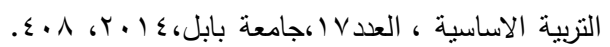

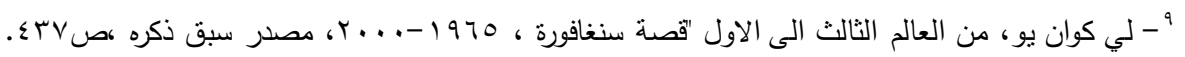

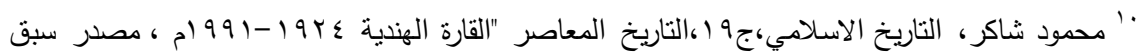

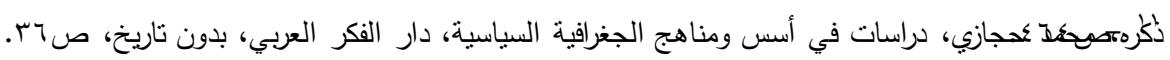

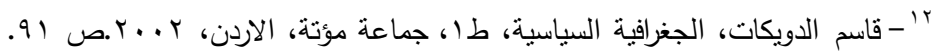

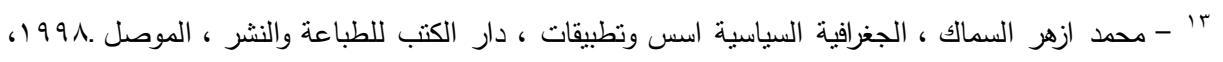

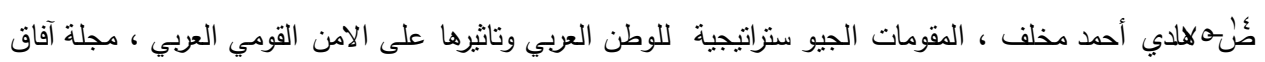

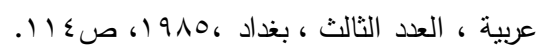
10

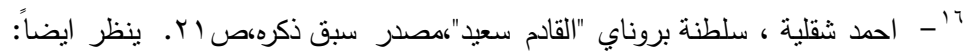

- Concise Atlas of the World. (2010) London. Collins Publishers.,p .116.

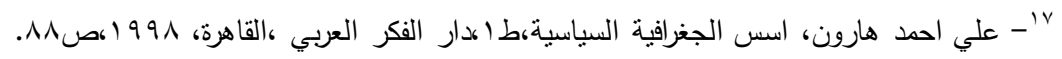

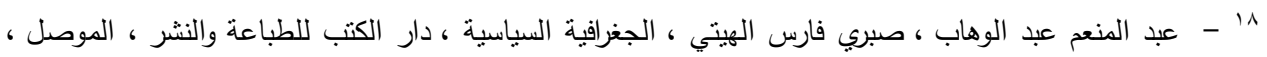

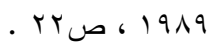
19 - عدنان السيد حسين ،الجغرافية السياسية والاقتصادية والسكانية للعالم المعاصر ، طب، المؤسسة الجامعية للاراسات

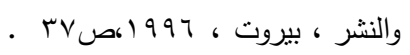

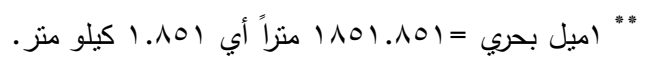

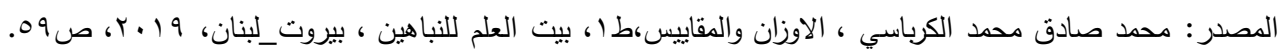


العدد الحادي والأربعون

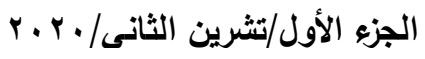

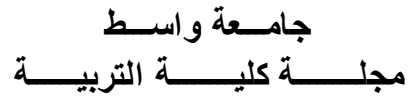

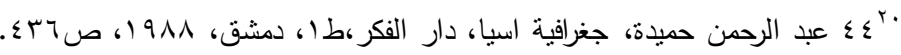

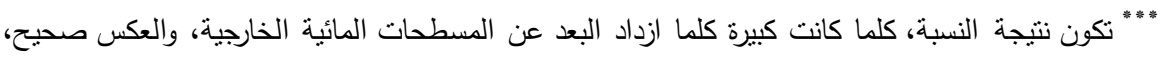

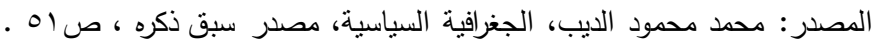

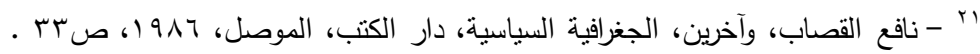

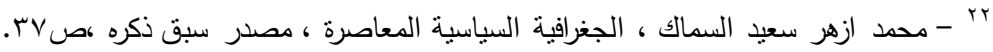

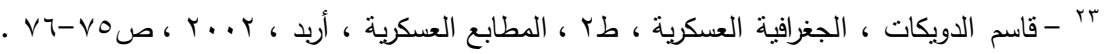

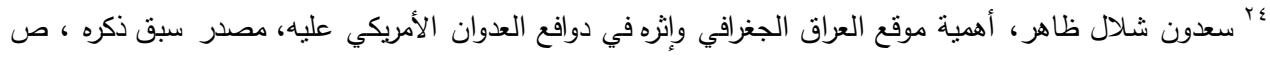

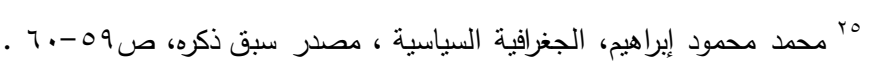

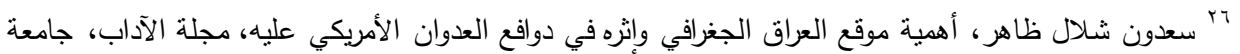

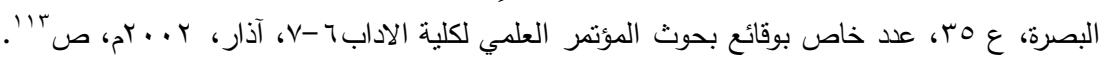

${ }^{27}$ Ango, Lydia. (1998). Basic Geography. PLACE OF PUBLICTION: Goodwill Trading Co., Inc.., 198, p. 38 .

10 Weigert, H. W. (1957) Principles of Political Geography: Appleton-Century. New York: Appleton-Century-Crofts. pp. $174-175$.

${ }^{29}$ Political Map of Brunei Darussalam", nations online.

${ }^{30}$ Population Distribution and Basic Demographic Characteristics, Malaysia, Dept. of Statistics. (1957 to 2010), p.5.

${ }^{31}$ Grounds, Norman J. (1972) Political Geography. New York: McGraw Hill., p.27. זr عبد علي الخفاف، جغرافية العالم الاسلامي:اسس عامة على المحيط الطبيعي والبشري، طا، دار الثروق للنشر،

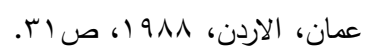

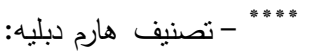

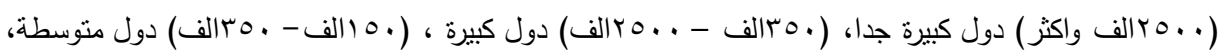

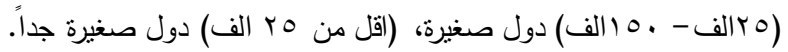

المصدر:

- Harm J.De Blij, Dystematic Political Geography. New York. John Wiley and Son, 1973, P. 39.

${ }^{33}$ Alexander, Lewis. In: M. Norman J. G. Pond. (1963). Political Geography. New York: McGraw Hill Book.,P.27

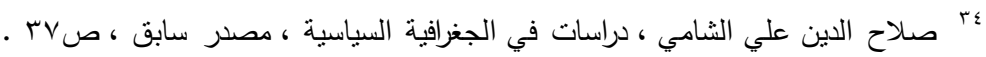

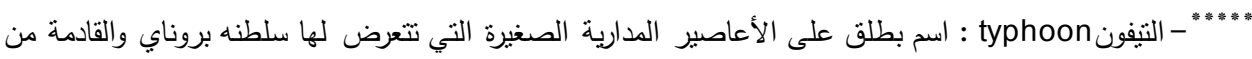

غرب المحيط الهادي وسواحل الصين الجنوبية الثرقية، وتبلغ سرعة الريح • ـ17 مث / ساعة، وتهطل أمطار غزيرة،

وتحدث عواصف رعدية.

المصدر: - المعاص

- J.G. Liou \& L. Y. Hsiao, Tectonic seting and Regionl Geology ofTaiwan, USGS, stanford university, 1999 .P.5 
العدد الحادي والأربعون

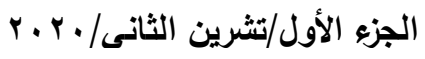

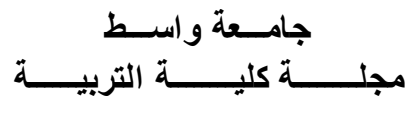

". - يقول راتزل :"أن كل دولة هي باتت في صراع مع العالم الخارجي للافاع عن الحيز space التي تشغله وهي

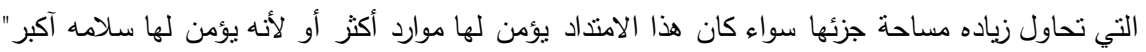

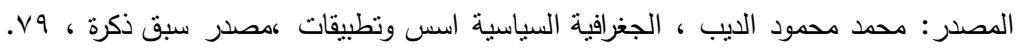

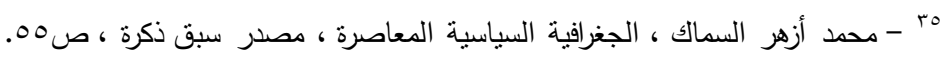

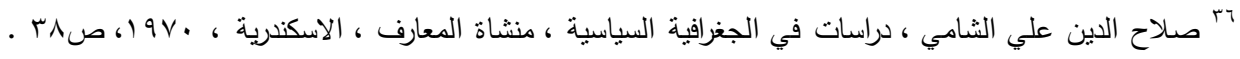

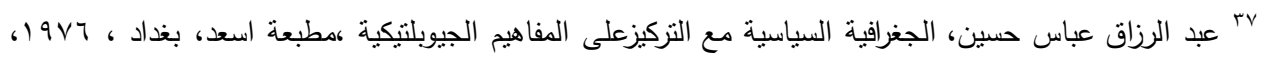

ص99.

" ***"." - هي منطقة النواة أو القلب الحيوي ، وتتميز تلك المنطقة بكثافة سكانها ووفرة إنتاجها وسهولة مواصلاتها

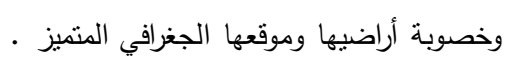

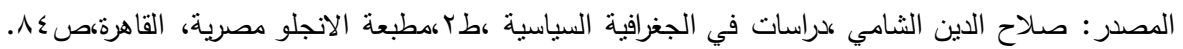

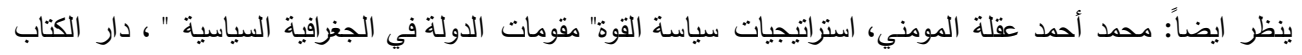

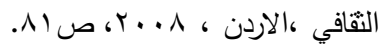

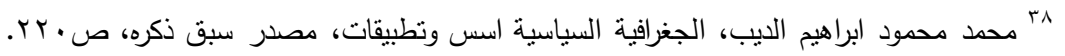

${ }^{39}$ Hoskins, Janet and De Raedt, Jules (eds.). (1996). Headhunting and the Social Imagination in Southeast Asia. California: Standford University Press, pp. 96-100.

${ }^{40}$ Department of Fisheries. (1992). The Integrated Manegement Plan for the Costal Zone of Brunei Darussalam, Vol. 7(29), Associations of Southeast Asian Nations, United States Coastal Resources, Manegement Project Technical, p. 17.

41 Dzurek, Daniel J. (1993). "The Spratly Islands Dispute, Who's on First": Maritime Briefing, China Quarterly, International Boundaries Research Unit, Durham University, UK, 2( 1), p. 22.

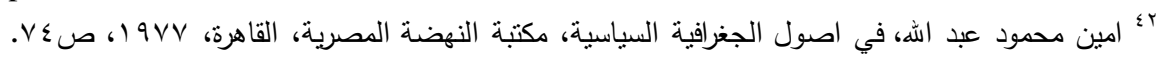

${ }^{43}$ Alexander, Lewis M. ,op.cit, PP42-43 .

ينظر أيضاً: أمين محمود عبد اله، في أصول الجغرافية السياسية، مصدر سبق ذكره، ص9 ؟ --0. .

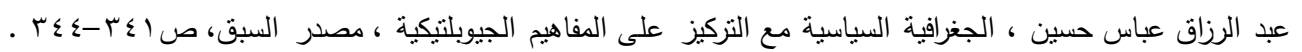

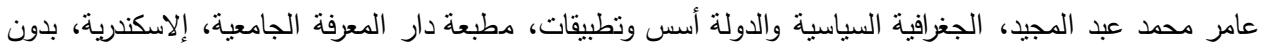

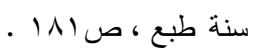

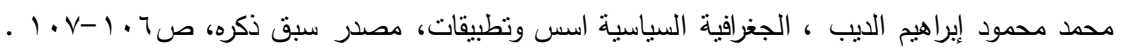

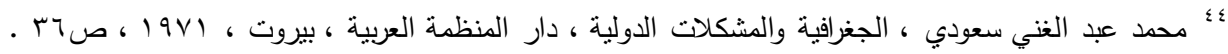

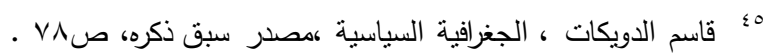

${ }^{46}$ Huntington, E. (1958). Mainsprings of Civilization. New York: Chapman \& Hall..

v؛ نافع القصاب وآخرين، المسرح الجغرافي لمنطقة الهضبة الغربية من العراق ومؤهلاته النتموية مصدر سبق ذكره ، ص بنظر أيضا: 


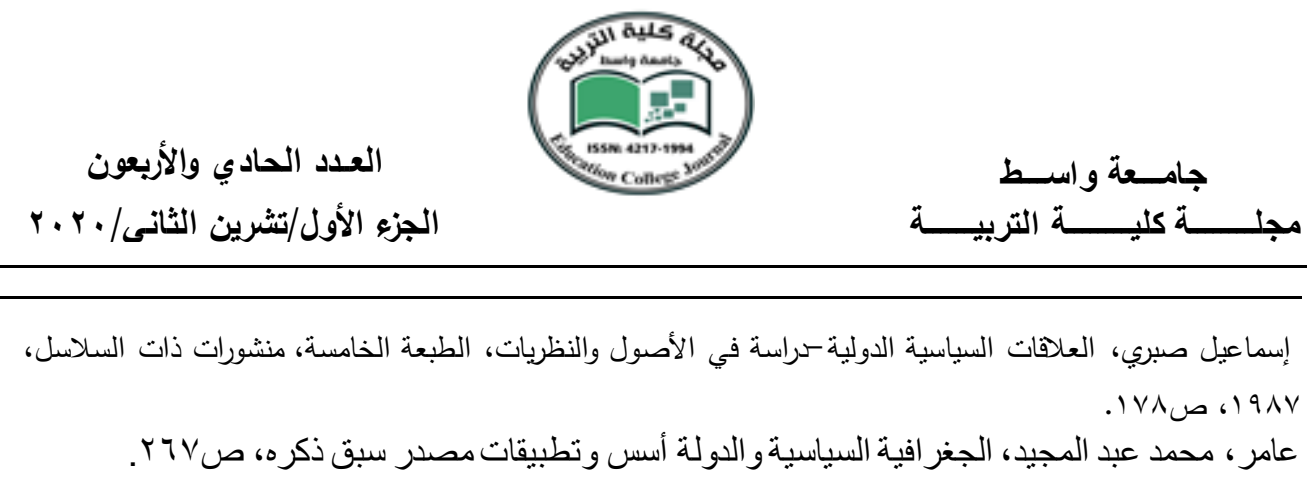

${ }^{49}$ Encyclopedia Britannica and Europa Year-Book. (1982). Vol. 3. Chicago: Pacific Publications,p341

${ }^{50}$ Metaxiotis, Kostas; Yigitcanlar, Tan; and Carrillo, Frabcisco Javier (ed.). (2006). Knowledge Cities: Approaches, Experiences and Prospective. Oxford: Lin acre House, pp. 31-32.

${ }^{52}$ Mark Cleary, Wong, Shuang Yann. (1994). Oil, Economic Development and Diversification in Brunei Darussalam. UK: Palgrave Macmillan. ,pp,51-54.

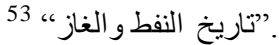

(2015).URL://https://translate.google.com/translate?hl=ar\&sl=en\&u=https://www.bsp.com.b $\mathrm{n} / \mathrm{main} /$ about-bsp/history-of-oil-gas \&prev=search\&pto=aue. Retrieved on Wed. 19, August, 2020.

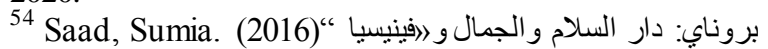
الثرق 93ba8160b7ed. Retrieved on Wed. 19, August, 2020. 